\title{
Multi-Index Image Differencing Method (MINDED) for Flood Extent Estimations
}

\author{
Eduardo R. Oliveira ${ }^{1}\left(\mathbb{D}\right.$, Leonardo Disperati ${ }^{2, *}{ }^{\mathbb{C}}$, Luca Cenci ${ }^{3,4}{ }^{\oplus}$, Luísa Gomes Pereira ${ }^{5}(\mathbb{D}$ and \\ Fátima L. Alves ${ }^{1}$ \\ 1 COPING TEAM - Coastal and Ocean Planning Governance, CESAM-Centre for Environmental and \\ Marine Studies, Department of Environment and Planning, University of Aveiro, 3810-120 Aveiro, Portugal; \\ eduardo.oliveira@ua.pt (E.R.O.); malves@ua.pt (F.L.A.) \\ 2 Department of Earth, Environmental and Physical Sciences, University of Siena, 53100 Siena, Italy \\ 3 CIMA Research Foundation, 17100 Savona, Italy; luca.cenci@cimafoundation.org \\ 4 Department of Information Engineering, Electronics and Telecommunications, Sapienza US, \\ 00184 Rome, Italy \\ 5 Águeda School of Technology and Management, Aveiro University, 3750-127 Águeda, Portugal; \\ luisapereira@ua.pt \\ * Correspondence: disperati@unisi.it; Tel.: +39-0577233736
}

Received: 3 May 2019; Accepted: 28 May 2019; Published: 31 May 2019

\begin{abstract}
Satellite remote sensing data are often used to extract water surfaces related to extreme events like floods. This study presents the Multi INDEx Differencing (MINDED) method, an innovative procedure to estimate flood extents, aiming at improving the robustness of single water-related indices and threshold-based approaches. MINDED consists of a change detection approach integrating specific sensitivities of several indices. Moreover, the method also allows to quantify the uncertainty of the Overall flood map, based on both the agreement level of the stack of classifications and the weight of every index obtained from the literature. Assuming the lack of ground truths to be the most common condition in flood mapping, MINDED also integrates a procedure to reduce the subjectivity of thresholds extraction focused on the analysis of water-related indices frequency distribution. The results of the MINDED application to a case study using Landsat images are compared with an alternative change detection method using Sentinel-1A data, and demonstrate consistency with local fluvial flood records.
\end{abstract}

Keywords: remote sensing; optical satellites; Landsat; change detection; flood mapping; Portugal

\section{Introduction}

Floods are amongst the most important weather-driven hazards, being capable of inducing considerable damage, including economic losses, and threatening of human lives [1]. The effects of floods are dependent on several factors, including flow velocity and depth. Even standing water can produce damage, depending on the persistence time and land cover affected (e.g., damages to crops). Floods may result from heavy or persistent rainfall, flooding by water bodies, water tables rising, snowmelt, or they may originate from artificial sources [2]. Mapping flood extent is, thus, important for several scientific (e.g., better understating of hydrological and, more generally, earth system science processes) and operational (e.g., emergency management; risk and damage assessment, insurance claims) applications.

Flood hazard modelling chains usually start with hydrologic modelling to obtain hydrographs for assigned return periods (e.g., the 100-year flow), which are consequently incorporated into hydraulic flow propagation models to estimate water surface elevations and corresponding inundation areas [3-6]. 
Therefore, knowing the extent of flood events is one of the main requirements of the whole modelling process. The use of remote sensing methods to extract water bodies from optical and microwave satellite data has been widely studied; the same principles generally apply for mapping flooded areas. Multispectral optical data may be used to identify distinctive spectral signatures of water features. Surface water is characterized by relatively higher reflectance values (ca. 0.1 or lower) in the visible region of the electromagnetic spectrum, with peaks occurring in the blue-green range, with respect to red and near-short (NIR-SWIR) wave infrared [7-10]. However, such responses tend to vary in the visible and NIR regions, depending on the water column depth, turbidity, dissolved organic compounds and eutrophication $[11,12]$. In the SWIR part of the spectrum, the absorption is very high (i.e., effectively black) independently of the water column characteristics. Moreover, this spectral interval shows better aerosol penetration capability, these conditions being particularly useful for implementing atmospheric correction methods for coastal and inland water-related studies [13-15]. Nevertheless, a strong limitation of optical sensors is their dependence on both sunlight and cloud conditions, which may reduce the possibility to acquire data during a flood event. However, the increasing availability of free moderate spatial resolution optical data (e.g., Landsat series and Sentinel 2 constellations) augments the number of possible acquisitions related to a given event under favorable weather conditions. Indeed, there are several operational remote sensing flood detection tools and services based on optical satellites (e.g., [16-19]).

Concerning microwave data, due to their almost all-weather, day and night imaging capabilities, active synthetic aperture radar (SAR) sensors (e.g., Cosmo SkyMed-CSK, Terra SAR-X, Sentinel 1 constellations) are the most employed tool for water extraction and mapping of flooded areas (e.g., [20-24]), as well as for operational purposes (e.g., [25-29]). In SAR images, flooded areas can be easily detected because their backscattering signal intensity is significantly lower compared to other surface features (e.g., non-flooded areas) imaged by the sensors. While smooth water surfaces reflect the incident radar signal with a specular scattering mechanism, non-flooded areas scatter the radar signal in multiple directions [30,31]. However, as discussed in [32], SAR applications suffer from several limitations. The delineation of flood areas can be complicated in transient shallow water areas, which produce gradual signal variation between flooded and non-flooded areas. Both wind and precipitation may cause the roughening of water surfaces, producing pulse returns which make difficult to delineate flooded areas correctly. Furthermore, the accurate extraction of flooded areas in urban environments can be affected by double bounce reflection of buildings. Moreover, it has been shown that X-band instruments (e.g., CSK and Terra SAR-X) can fail in discriminating flooded areas from the microwave radar signature of rain because of the attenuation of the radar signal by heavy precipitation events [29]. Surface absorption/attenuation due to snow or very dry sand surfaces can also produce low backscatter values (i.e., dark areas) that can be erroneously classified as flooded areas, thus generating false alarms [29,33]. Finally, also data processing of shadowing effects in areas characterized by complex topography may result in the occurrence of low backscatter values. In addition to all of this, SAR images are affected by speckle noise that complicates their interpretation, due to the coherent nature of the signal, if compared with optical images of the same target [30].

The main objective of this study is to improve the estimation of flood extent by means of a satellite remote sensing method, integrating several water-related indices in a change detection method. The method, hereinafter referred as Multi INDEx Differencing (MINDED), was developed to be applied to multispectral satellite data acquired from different optical sensors, characterized by the presence of VIS, NIR SWIR bands, including the freely available entire Landsat series, the Advanced Spaceborne Thermal Emission and Reflection Radiometer (ASTER) and Sentinel-2. In order to reach as many users as possible, the procedure has been implemented through open-source software. MINDED was applied to a study area in Northwestern Portugal, and the results were compared with flooding maps obtained by the Hierarchical Split-Based Approach (HSBA) [26], a flood detection algorithm provided by the GPOD HASARD Sentinel-1 service. 


\subsection{Flood Extent Estimation Methods Based on Remote Sensing Imagery}

The definition of flood, e.g., "temporary covering by water of land not normally covered by water" [34], conceptually implies the occurrence of a certain type of change over time. Digital change detection techniques based on remote sensing imagery are capable of providing both long-term and short-term solutions $[35,36]$. Long-term change detection approaches consist of temporal trajectory analysis (also referred as trends), using long series of observation data, which can be used to detect subtle anomalies in annual variability of climatic variables, such as those resulting from climate change [37]. However, that is not the case of floods, which can happen within a few days or hours. Bi-temporal change detection analysis includes several methods capable of dealing with such short-term phenomena [35,38-40] (as summarized in Table 1).

Table 1. Advantages and disadvantages of bi-temporal change detection methods.

\begin{tabular}{|c|c|c|}
\hline Method & Advantages & Disadvantages \\
\hline $\begin{array}{l}\text { Post classification } \\
\text { comparisons }\end{array}$ & $\begin{array}{l}\text { Wide application [35]. Implemented by } \\
\text { processing either single or multiple bands } \\
\text { (including spectral relationships) [35]. }\end{array}$ & $\begin{array}{l}\text { Not ideal for analyzing the process of } \\
\text { flooding and post-flooding events, due to the } \\
\text { spatially continuous variation of soil } \\
\text { wetness [39]. }\end{array}$ \\
\hline $\begin{array}{l}\text { Multi-temporal } \\
\text { spectral unmixing }\end{array}$ & $\begin{array}{l}\text { Makes it possible to determine the water } \\
\text { proportion changes in every pixel (flood } \\
\text { detection) [35]. }\end{array}$ & $\begin{array}{l}\text { More complex and less straightforward for } \\
\text { mapping purposes (compared to other hard } \\
\text { classification techniques). } \\
\text { Difficulty in defining classes of change. } \\
\text { Requires a priori information about the study } \\
\text { area and end-members [38]. }\end{array}$ \\
\hline Data transformation & $\begin{array}{l}\text { Transformations are capable of sorting } \\
\text { modifications of state according to different } \\
\text { orders (including those resulting from } \\
\text { water-related conditions) [40]. }\end{array}$ & $\begin{array}{l}\text { Finding the meaning for each order of change } \\
\text { is often a complex task and requires a deep } \\
\text { knowledge of the study area } \\
\text { (scene-dependent) [40]. }\end{array}$ \\
\hline Change vector & $\begin{array}{l}\text { Multivariate technique, capable of } \\
\text { simultaneously incorporating multiple layers. } \\
\text { Great potential to recognize and analyze the } \\
\text { amount and type of changes [35]. }\end{array}$ & $\begin{array}{l}\text { Selection of different thresholds is in practice } \\
\text { very complex [35]. }\end{array}$ \\
\hline Image ratioing & $\begin{array}{l}\text { Pixel-by-pixel based analysis of either } \\
\text { two-date images or image } \\
\text { transformations }[35,41] \text {. }\end{array}$ & $\begin{array}{l}\text { The non-normal distribution of results has } \\
\text { been criticized for being statistically invalid, } \\
\text { preventing the computation of thresholds } \\
\text { based on standard deviation functions }[35,41] \text {. }\end{array}$ \\
\hline $\begin{array}{l}\text { Univariate image } \\
\text { differencing }\end{array}$ & $\begin{array}{l}\text { Wide application [35]. } \\
\text { Despite its simplicity, it can achieve better } \\
\text { performances compared to other } \\
\text { methods [41]. }\end{array}$ & $\begin{array}{l}\text { Unable to directly specify the type of } \\
\text { change [41]. }\end{array}$ \\
\hline
\end{tabular}

Univariate image differencing is the most widely applied bi-temporal approach. It consists of subtracting spectral or transformed data (e.g., using water-related indices), producing positive and negative values, depending on the type of change [35]. In theoretical and ideal conditions, no-change areas should result in zero values; however, in real conditions, this is not the case as an effect of spatial and spectral co-registration errors, as well as natural time-dependent changes. One or more thresholds may be required to define two or more classes of change (density-slicing), which may provide hints about amounts and types of change [41].

Both optical and SAR data can be used to detect floods using bi-temporal change detection methods, which consist of comparing images acquired before and after a certain event. In principle, the images pre-dating the event should be the most recent from the available dataset, while the post-event the oldest. Regarding the pre-event images, a wide period between acquisition and the event will also imply natural changes resulting from phenological cycles as well as seasonal water body variations [12]. As for the post-event images, the corresponding time span should be as short as possible in order to record the most accurate picture of the flooded area. However, it can be difficult to obtain optical satellite imagery approximately coeval to flood occurrence, since hydro-meteorological 
events are typically associated with clouds and long periods of adverse weather conditions. Concerning SAR data instead, when applying change detection methods, particular attention must be paid for taking into account all the differences between the image changes occurred to the image's targets (e.g., a comparison between images acquired by the same sensor but with different orbit/geometry of acquisitions).

\subsubsection{Optical Water-Related Indices}

Many optical Water-related Indices (WrI) have been defined and applied in the literature to detect surface water from remote sensing imagery. This section introduces those most commonly found in flood-related literature.

The Normalized Difference Vegetation Index (NDVI) [42], is obtained with spectral bands corresponding to Red and NIR regions. Without being specific for water detection purposes, it has a theoretical threshold of zero, being the negative values generally associated with water occurrence.

The Normalized Difference Water Index (NDWI) [7] is one of the first specific indices to detect water, considering Green and NIR bands in a similar structure to the NDVI. The NDWI includes the same theoretical threshold of zero, but with positive values being interpreted as water. The Modified Normalized Difference Water Index (MNDWI) was proposed by [43], as an alternative to the NDWI, using SWIR (e.g., band 5 of Landsat TM) instead of the NIR band. The MNDWI has become one of the most popular water detection indices [44].

The Automated Water Extraction Index (AWEI) [45] was conceived for sensors covering the visible to SWIR electromagnetic spectrum range and consists of multiple subtractions and additions of bands through several empirically based coefficients, developed to maximize the separability between water and non-water pixels. It was developed to improve classification accuracy in areas including shadow and dark surfaces, where most other indices tend to fail. It includes two versions: the 'AWEI no shadow' (AWEI_NS) for situations where shadows are not major problems and the 'AWEI shadow' (AWEI_S) intended to effectively eliminate shadows or other dark surfaces [44]. Both versions were developed for a theoretical imposed threshold of zero, with water pixels corresponding to positive values. Nevertheless, as with other indices, in practice, the optimal threshold is usually scene-dependent.

The Tasseled Cap method was first developed by [46] for Landsat MSS sensor and then applied to Landsat TM [47]. It consists of a multispectral sensor-based transformation which makes it possible to obtain new outputs such as Brightness, Greenness, and Wetness. Tasseled Cap Wetness (TCW) [48] can be used to identify water, using a theoretical value of zero to separate water (positive values) from non-water pixels [49]. TCW is usually obtained with sensor-specific coefficients applied to either Top of Atmosphere (TOA) (e.g., [50,51]) or ground reflectance [52].

Table 2 summarizes the main advantages and disadvantages of each of the previous WrI as resulting from the literature. Despite the overall advantages, there are additional challenges for flood detection purposes. Suitability and accuracies of each index are affected by local conditions, which, depending on the study area heterogeneity, may vary within short distances (e.g., land cover type, topography, atmospheric conditions).

Table 2. Advantages and disadvantages of optical Water-related Indices (WrI).

\begin{tabular}{|c|c|c|c|}
\hline WrI Name & Advantages & Disadvantages & Equation \\
\hline NDVI [42] & $\begin{array}{l}\text { Improved detection capacity with mixed } \\
\text { water and vegetation [53] }\end{array}$ & Less suited for water detection $[7,39]$ & $\begin{array}{c}\text { NDWI }=(\text { GREEN - } \\
\text { NIR }) /(\text { GREEN + NIR })\end{array}$ \\
\hline NDWI [7] & $\begin{array}{l}\text { Good performance in mountain shadow } \\
\text { areas [54] } \\
\text { Good overall accuracy }[55,56] \\
\text { Good performance in large urban areas } \\
\text { with cloud-free conditions [49] }\end{array}$ & $\begin{array}{l}\text { Weaker abilities to extract water bodies [54] } \\
\text { Sensitive to built-up land signals, which } \\
\text { often results in an overestimation of water } \\
\text { bodies [55] }\end{array}$ & $\begin{array}{c}\text { MNDWI }=(\text { GREEN }- \\
\text { SWIR1)/(GREEN + } \\
\text { SWIR1) }\end{array}$ \\
\hline MNDWI [43] & $\begin{array}{l}\text { The capacity of removing interferences of } \\
\text { built-up feature signals }[55,56] \\
\text { Better suited for open water mapping [55] }\end{array}$ & $\begin{array}{l}\text { High variability of optimal thresholds [55] } \\
\text { Unable to remove certain shadow noises } \\
\text { effectively [55] }\end{array}$ & $\begin{array}{c}\mathrm{NDVI}=(\mathrm{NIR}- \\
\mathrm{RED}) /(\mathrm{NIR}+\mathrm{RED})\end{array}$ \\
\hline
\end{tabular}


Table 2. Cont

\begin{tabular}{|c|c|c|c|}
\hline WrI Name & Advantages & Disadvantages & Equation \\
\hline AWEI [45] & $\begin{array}{l}\text { Good performance in large urban } \\
\text { areas [49] }\end{array}$ & $\begin{array}{l}\text { Difficulty in finding optimal thresholds [38] } \\
\text { Unable of totally removing mountain } \\
\text { shadows [38] } \\
\text { May misclassify high albedo } \\
\text { surfaces }[44,45,55]\end{array}$ & $\begin{array}{c}\text { AWEI_NS }=4 \times(\text { GREEN } \\
- \text { SWIR1 })-(0.25 \times \text { NIR } \\
+2.75 \times \text { SWIR1 })\end{array}$ \\
\hline TCW [48] & Good ability to extract water bodies [54] & Fails to suppress mountain shadow [54] & $\begin{aligned} \mathrm{TCW}= & \mathrm{aB} 1+\mathrm{bB} 2+\ldots \\
& +\mathrm{iBj} *\end{aligned}$ \\
\hline
\end{tabular}

* Sensor dependent (examples given in Table 3).

Table 3. Examples of Tasseled Cap Wetness (TCW) coefficients for different optical satellite sensors.

\begin{tabular}{|c|c|c|c|}
\hline Sensor & Data & TCW Coefficients & Reference \\
\hline Landsat 4 TM; Landsat 5 TM & Reflectance Factor & $\begin{array}{l}0.0315 \mathrm{~B} 1+0.2021 \mathrm{~B} 2+0.3102 \mathrm{~B} 3+0.1594 \mathrm{~B} 4+ \\
0.6806 \mathrm{~B} 5-0.6109 \mathrm{~B} 7\end{array}$ & [48] \\
\hline Landsat 7 ETM+ & At-satellite reflectance & $\begin{array}{l}0.2626 \mathrm{~B} 1+0.2141 \mathrm{~B} 2+0.0926 \mathrm{~B} 3+0.0656 \mathrm{~B} 4- \\
0.7629 \mathrm{~B} 5-0.5388 \mathrm{~B} 7\end{array}$ & {$[51]$} \\
\hline ASTER & At-satellite reflectance & $\begin{array}{l}0.166 \mathrm{~B} 1-0.087 \mathrm{~B} 2-0.703 \mathrm{~B} 3+0.187 \mathrm{~B} 4+0.040 \mathrm{~B} 5 \\
+0.500 \mathrm{~B} 6-0.287 \mathrm{~B} 7+0.030 \mathrm{~B} 8-0.318 \mathrm{~B} 9\end{array}$ & [57] \\
\hline SPOT-5 & At-satellite reflectance & $0.397 \mathrm{~B} 1+0.260 \mathrm{~B} 2+0.118 \mathrm{~B} 3-0.872 \mathrm{~B} 4$ & [58] \\
\hline Landsat 8 OLI & At-satellite reflectance & $\begin{array}{l}0.1511 \mathrm{~B} 2+0.1973 \mathrm{~B} 3+0.3283 \mathrm{~B} 4+0.3407 \mathrm{~B} 5- \\
0.7117 \mathrm{~B} 6-0.4559 \mathrm{~B} 7\end{array}$ & {$[50]$} \\
\hline Sentinel-2 & At-satellite reflectance & $\begin{array}{l}0.0649 \mathrm{~B} 1+0.1363 \mathrm{~B} 2+0.2802 \mathrm{~B} 3+0.3072 \mathrm{~B} 4+ \\
0.5288 \mathrm{~B} 5+0.1379 \mathrm{~B} 6-0.0001 \mathrm{~B} 7-0.0807 \mathrm{~B} 8- \\
0.0302 \mathrm{~B} 9+0.0003 \mathrm{~B} 10-0.4064 \mathrm{~B} 11-0.5602 \mathrm{~B} 12- \\
0.1389 \mathrm{~B} 8 \mathrm{~A}\end{array}$ & [59] \\
\hline
\end{tabular}

Regardless of the method chosen, mixed pixels are a common problem affecting remote sensing applications, particularly those resulting from moderate spatial resolution (e.g., $30 \mathrm{~m}$ ) satellite images [60]. As referred by [49], another limitation of water classification methods concerning the handling of the variability of reflectance spectra which changes according to water properties (e.g., concentrations of phytoplankton and sediments, depth, or substratum type). Another difficulty relates to the discrimination between shadows cast and clouds, and the steep topography, quarries and tall buildings, which may produce signals similar to those of water. In the case of flood analysis, the presence of clouds and cloud shadows are very common, and one of the first steps should be masking such features (e.g., [61,62]).

For reproducibility reasons, when analyzing different epochs and locations, the simplest approach would be to use single global thresholds for each WrI. Finding an optimal scene-dependent threshold may provide better accuracy, even though this can be a difficult task due to high temporal and spatial variability [39].

\subsubsection{Flood-Related Synthetic Aperture Radar Applications}

According to [33], the use of a simple global threshold is the most frequent approach in flood delineation from SAR imagery. Although this approach can be easily implemented, and thus, is particularly suitable for operational applications related to flood risk emergency management, the criteria used for defining the threshold value affect drastically flood mapping results [30]. Such approaches for image thresholding can be based on the visual inspection of the grey-scale frequency histogram [63-66], or automatic algorithms (e.g., [67,68]). Given the recently increased availability of SAR images, in the last years, several thresholding methods for flood detection have been developed $[26,27,30,69-71]$. These methods exploit the characteristics of SAR systems to produce image histograms which are characterized by a bimodal distribution (representative of the classes flooded/non-flooded) that can be used to define an optimal threshold for detecting inundated areas $[26,29,30,69,70]$. Such rational can be applied both to a multitemporal dataset (change detection methods) or to a single-event image. In the first case, the flood mapping algorithm can be represented 
as a binary classification problem in which the "change" class (i.e., the flooded area) must be resolved from the "no change" class (which represents the "background" dominant class of the image) [30]. In the second case, instead, the water/flooded pixels correspond to the darker areas of the image that must be discriminated from the other (surrounding) land cover classes which are characterized by higher backscattering values [72].

\section{Proposed Method}

\subsection{MINDED: the Multi-Index Differencing Approach}

The Multi-INDEx Differencing (MINDED) method for flood areas detection, illustrated in Figure 1, combines several WrI in a change detection approach, as an alternative to the single WrI analysis commonly found in the literature. This method has the objective of integrating the strengths of each index and considers the agreement level among outputs obtained by different indices as an indicator of overall uncertainty. The structure of MINDED is demonstrated using six of the most common WrI found in the literature. Nevertheless, the same theoretical principles of the method should apply if other indices are to be considered.

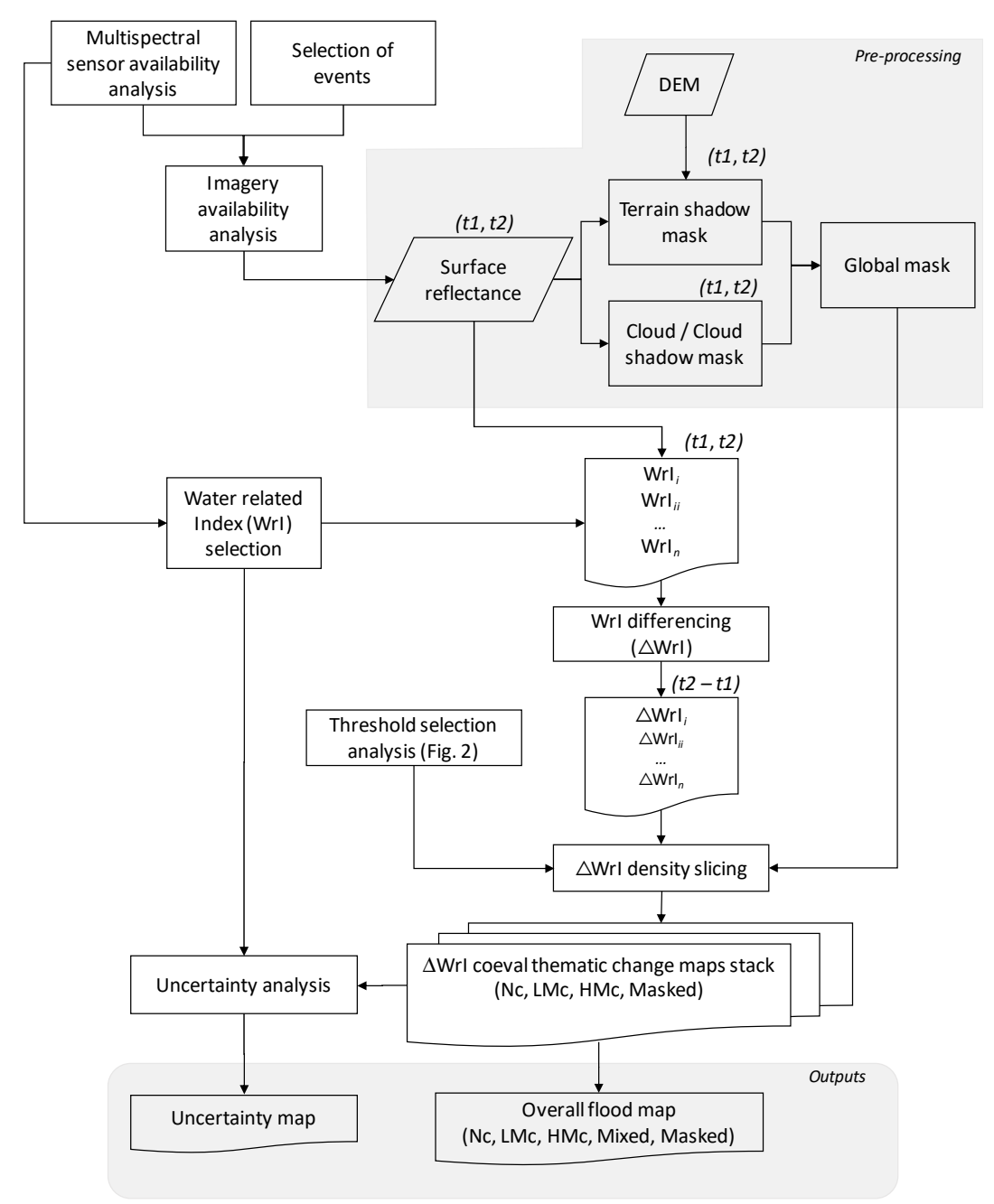

Figure 1. The Multi-INDEx Differencing (MINDED) method workflow.

In order to define the study area and the imagery dataset to process, as a preliminary step, we assume that a certain area could have experienced a flooding event within a certain period. 
If historical flood records are not available, other indirect data sources may be considered (e.g., precipitation measurements, river water levels, local news).

For flooded areas, WrI variation occurs between the epochs $t 1$ and $t 2$ (respectively prior and after the given flood event). For a change detection method based on image differencing, no-change areas $(\mathrm{Nc})$ are theoretically represented by the digital value zero. Assuming the time span $(t 2-t 1)$ is reasonably short, in principle, Nc should be the majority of the pixel image distribution, corresponding to the modal value of the frequency distribution. In contrast, digital values different to zero represent change areas, and they tend to be located toward both tails of the frequency distribution. When WrI differencing $(\Delta \mathrm{WrI})$ is used, we expect to locate flooded areas changes in only one of the tails, either positive (e.g., $\triangle \mathrm{NDWI}, \triangle \mathrm{MNDWI}, \triangle \mathrm{TCW}, \triangle \mathrm{AWEI}$ ), or negative (e.g., $\triangle \mathrm{NDVI}$ ) (Figure 2). The higher the distance from the modal $\Delta \mathrm{WrI}$ value, the higher the magnitude of change, until a complete change of state from dry to flooded surface. If only such kind of flood changes occur, this results in an ideal bi-modal distribution of the function $(f)$ where the discrimination between Nc and flooded areas is unambiguous (thresholding interval-Figure 2a). In practice, different flooding conditions (water thickness and suspended materials, water surface roughness), as well as different initial conditions (land cover, substrate properties, surface roughness and wetness, and their spatial distribution in respect to pixel size), imply a continuous distribution of $\Delta \mathrm{WrI}$ values beyond Nc (Figure 2b). Moreover, when analyzing the frequency distribution, one should also take into account the effect of the spatial-spectral misregistration between $t 1$ and $t 2$ imagery, changes resulting from phenomena other than flooding, and finally the effective sensitivity of WrI to detect surface water. The main consequence of these conditions is that the real distribution of Nc is represented by a bell-shaped range of $\Delta \mathrm{WrI}$ values located around zero (Figure 2c,d).

Given the above considerations and the fact that image differencing prevents discriminating among the types of change, but only change signal and intensity, we assume to classify flooded areas into the categories Low-Magnitude change (LMc) and High-Magnitude change (HMc) as a function of the $\Delta \mathrm{WrI}$ value (Figure $2 b-d$ ). This assumption requires the definition of two thresholds, between Nc-LMc (TL) and LMc-HMc (TH), which are then used to apply density slicing $[10,41]$ to the multitemporal imagery. These thresholds should be ideally defined with analysis of ground truth data. If such information is not available, thresholds may be obtained by only analyzing the frequency distribution of data. The latter approach is a key point of MINDED, allowing us to perform semi-automatic remote sensing procedures to extract flooded area extent from satellite imagery. We assume that these thresholds correspond to a sudden variation of $\Delta \mathrm{WrI}$ frequency, which is a consequence of the effects that the appearance of water-related conditions may induce on sets of pixels. The variation may be more (Figure 2c) or less (Figure 2d) pronounced depending on the occurrence of change-related secondary modal values. In the first case, the first order derivative of the function $(d f)$ is a useful tool to define the thresholds which are assumed to be located where the change of signs of $d f$ occurs. In other cases (Figure 2d), $d f$ continuously approaches zero without reaching it. Therefore, we chose as a threshold the $\Delta \mathrm{WrI}$ value where the second order derivative function $(22 f)$ reaches a local maximum, corresponding to a sudden variation of both $f$ and $d f$. In this approach, we assumed that this option would ensure the reproducibility of the method while reducing its subjectivity. In practice, for a given scene differencing, the distribution of $\Delta \mathrm{WrI}$ may follow both the conditions of Figure 2c, d around either TL or TH.

Without ground truth information, the interpretation of HMc may be nonetheless considered quite obvious, because it should represent a complete change of state from dry land to water surface. However, the same does not apply to LMc, which may be expected to represent pixels changing from dry to wet/saturated surfaces, as well as wet/saturated to water surfaces. Moreover, depending on the duration of the time span $(t 2-t 1)$, LMc may also correspond to those flooded areas that underwent drying/drainage processes after the flooding event. This is particularly interesting for those situations whenever it is impossible to obtain cloud-free satellite images immediately after a flood event. Finally, Nc areas are expected to include permanent water bodies, continuously wet/saturated surfaces, as well as any other kind of permanently dry surfaces. 

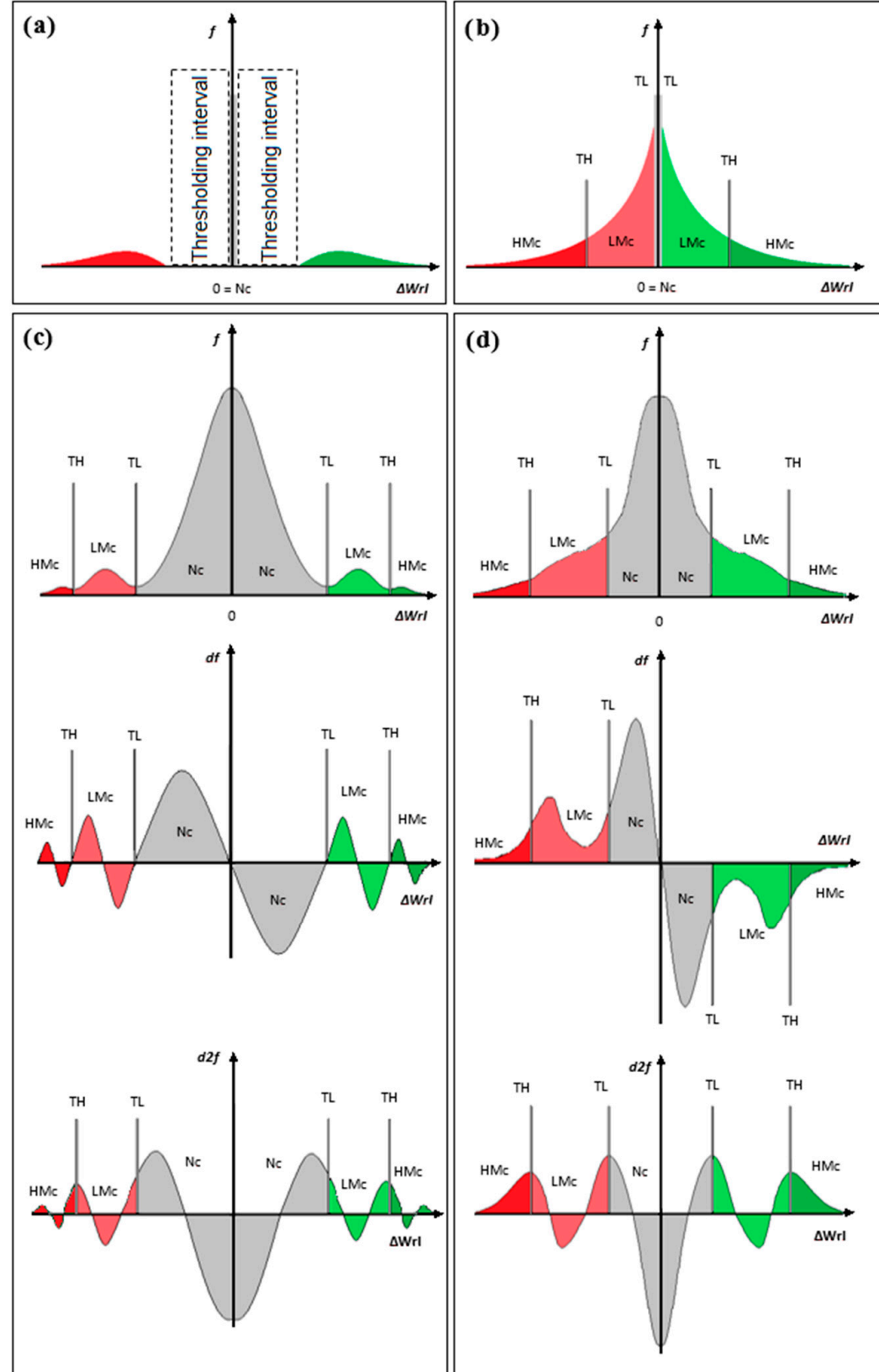

Figure 2. Density slicing classification (Nc-No change; LMc-Low-Magnitude change; HMc-High-Magnitude change) and threshold selections (TL-threshold between Nc-LMc; $\mathrm{TH}$-threshold between LMc-HMc) for different types of frequency $(f)$ distribution histograms of $\Delta$ WrI: (a) Ideal perfect distribution: no misregistration effects, perfect separation between Nc and change areas; (b) Ideal distribution: no misregistration effects, gradual transition from Nc to change; (c) Real distribution 1: misregistration effects, gradual well separated transition from Nc to change, and corresponding first $(d f)$ and second order $(d 2 f)$ derivatives; (d) Real distribution 2: misregistration effects, gradual change from Nc to change, and corresponding first and second order derivatives.

WrI are determined for $t 1$ and $t 2$ using the corresponding spectral bands (Table 2 ). As for TCW the equation and parameters of transformation are sensor-dependent (examples are given in Table 3).

After calculating $\triangle \mathrm{WrI}$, we perform density slicing based on TL and TH, to obtain a stack of six coeval thematic change maps. These maps represent changes caused by flooding according to each WrI specific sensitivity. The stack is then analyzed to extract two outputs, the Overall flood map and the Uncertainty map. 
The Overall flood map integrates the information from each WrI and is obtained by picking the absolute majority among the frequency of the change classes Nc, LMc, HMc (at least four consistent classifications over six). If an absolute majority does not occur, pixels are classified as 'Mixed'.

The Uncertainty map is obtained by Equation (1) which integrates pixel statistics of change classes within the stack, together with WrI specific average a priori accuracies $\left(A c c_{W r I}\right)$ obtained from literature values (Table 4),

$$
\rho_{i}=\sum A c c_{W r I}-\max \left\{\begin{array}{l}
\sum_{W r I=\mathrm{Nc}} A c c_{W r I} \\
\sum_{W r I=\mathrm{LMc}} A c c_{W r I} \\
\sum_{W r I=\mathrm{HMc}} A c c_{W r I}
\end{array}\right.
$$

where $i$ is a given pixel and $\rho_{i}$ its uncertainty of change classification. This implies that the parameter $A c c_{W r I}$ is a weighting factor for change classification statistics (count), while $\sum A c c_{W r I}$ is the limiting value for the definition of the uncertainty scale range. The expected range of $\rho_{i}$ is $0-\approx 3.8$, where $\rho_{i}=0$ represents the lowest uncertainty corresponding to six each-other coherent change classes. This approach also handles pixel statistical ties, by choosing the combination of indices which provides the highest cumulative $A c c_{W r I}$.

Table 4. Average a priori WrI accuracies for water detection, obtained from the literature, in percentage (Sources: $[44,49,55,56])$.

\begin{tabular}{cccccc}
\hline \multirow{2}{*}{ Index } & \multicolumn{4}{c}{ Literature Accuracies } & \multirow{2}{*}{ Average A Priori Accuracy $($ Acc $W r I)$} \\
\cline { 2 - 5 } & {$[44]$} & {$[49]$} & {$[55]$} & {$[56]$} & \\
\hline NDWI & 0.938 & 0.946 & 0.950 & 0.995 & 0.957 \\
MNDWI & 0.968 & 0.967 & 0.934 & 0.920 & 0.947 \\
NDVI & 0.933 & - & - & 0.990 & 0.961 \\
TCW & - & 0.966 & 0.918 & - & 0.942 \\
AWEI_NS & 0.967 & 0.975 & 0.941 & 0.953 & 0.959 \\
AWEI_S & 0.967 & 0.984 & 0.943 & 0.953 & 0.962 \\
& & & & $\sum A c c_{W r I}$ & 5.728 \\
\hline
\end{tabular}

\subsection{Pre-Processing Considerations}

As with any change-detection methods, geometrically corrected surface reflectance data should be used as inputs to implement the MINDED method correctly. When these products are not available, additional preprocessing steps are required, i.e., geometric co-registration and radiometric calibrations $[10,73]$.

In principle, the implementation of MINDED should be applied to cloud-free areas, while minimizing the time span $(t 2-t 1)$, in order to reduce the influence of other changes than those caused by flooding (e.g., phenological cycles, land cover modifications) [35]. This is made by choosing the newest image pre-dating and the oldest post-dating the flood event. In practice, a trade-off between time span duration and cloud coverage has to be applied.

Regardless, considering the characteristics of optical satellite imagery and the sensitivity of water detection indices, before implementing MINDED, preprocessing is necessary to extract a global mask including clouds, cloud shadows, and topographic shadows. Both cloud and topographic shadows are dark areas with very low reflectance values in the same bands, where the water spectral signature is also characterized by low values [73-75]. For this reason, most WrI are susceptible to collect such features as water, and it is necessary to mask such pixels.

Regarding clouds and cloud shadows, there are several options which can be applied. Whenever available, sensors providing products containing cloud cover and shadow cover data can be used directly to perform masking (e.g., Landsat 4-7 and 8 Level-2, or Sentinel-2 Level-1C). Otherwise, sensor specific procedures may be used, particularly single-epoch-based methods (e.g., [74-80]), which may be applied to preprocess both $t 1$ and $t 2$ images before implementing MINDED. 
Topographic shadows can be deduced from sun elevation and azimuth parameters that are usually included in satellite products metadata. In order to perform topographic shadows masking, these parameters are integrated with a Digital Elevation Model (DEM), e.g., the Shuttle Radar Topography Mission (SRTM) Version 3.0 1-arc-sec DEM [81], the Advanced Spaceborne Thermal Emission and Reflection Radiometer (ASTER) GDEM [82], the ALOS World 3D (AW3D30) Global DEM [83], or the Multi-Error-Removed Improved-Terrain DEM (MERIT) [84].

\section{Study Area: The Aveiro Region (Portugal)}

The Aveiro Region was chosen due to its context of recurrent floods and non-complex topography, presenting a favorable context for remote sensing-based flood detection. It is located on the Northwestern part of continental Portugal (Figure 3), being part of the Mediterranean Biogeographical region, nearby the border with the Atlantic zone. It is characterized by a temperate Mediterranean climate under maritime influence [1].

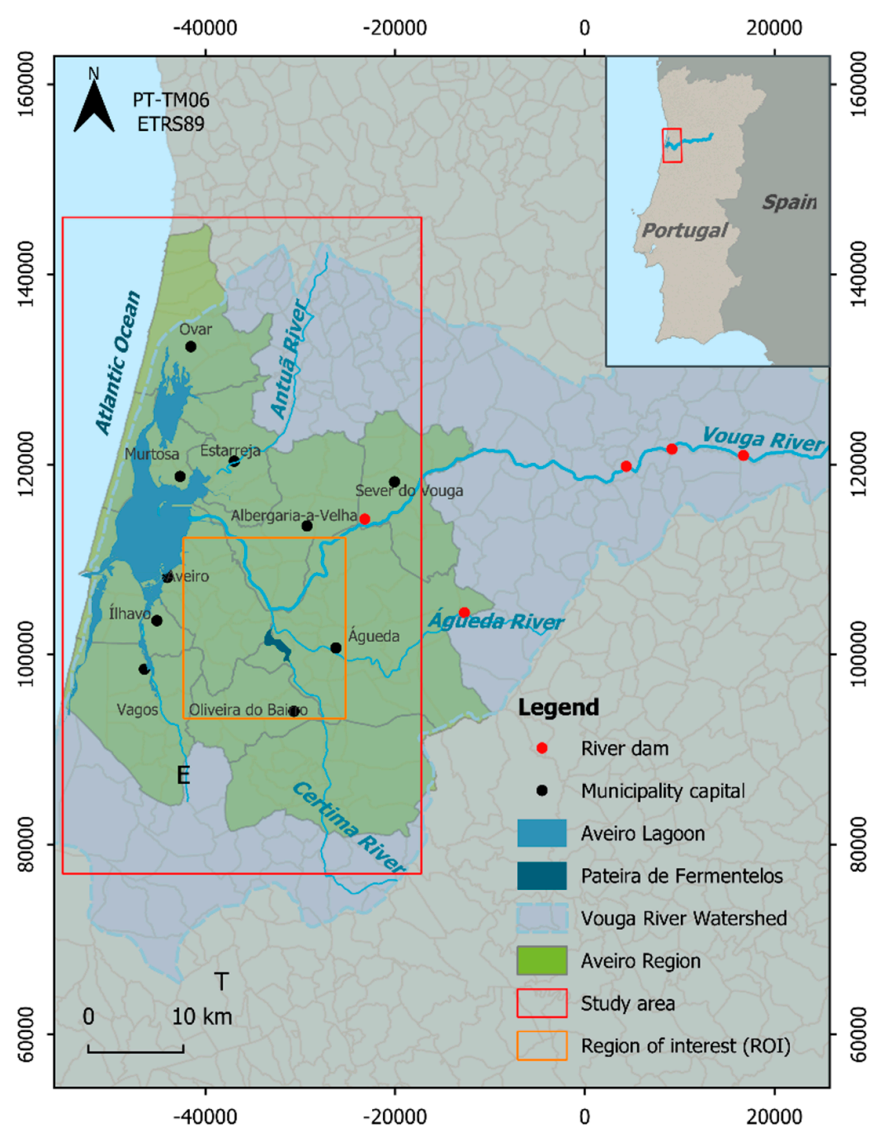

Figure 3. Study area location (Source: CAOP, Atlas do Ambiente, DQA, OpenMaps). Meteorological stations Estrada (E) and Tentugal (T) used for wind speed monitoring (Coordinate system: PT-TM06/ETRS89).

The study area includes the 11 municipalities of the Baixo Vouga Subregion (NUTS III), corresponding to the lower section of the Vouga River Watershed. This river is the main fluvial course draining into the Aveiro Lagoon, a shallow coastal lagoon, with a length of $45 \mathrm{~km}$ (N-S direction) and a maximum width of $10 \mathrm{~km}$ (W-E direction) [85]. The lagoon and adjacent areas are recognized as a complex system, integrating urban areas and a wide range of natural and semi-natural habitats, classified as a Special Protection Area (Natura 2000 Network) and Site of Community Importance [86].

Moreover, the study area includes another shallow natural lagoon, the Pateira de Fermentelos. It is classified as a Ramsar Site and is a part of the lowland area of the Cértima River, immediately 
located on the confluence with the Águeda River (an affluent of the Volga River). Due to its relatively compact and elongated catchment area, the Águeda River induces inflow to the Pateira de Fermentelos, producing floods during heavy rain events [87]. At about $2.5 \mathrm{~km}$ to the east, is located Águeda, one of the largest cities of the study area, which, despite successive efforts of authorities, it is known for being regularly affected by urban floods.

Within the study area, the following municipalities are recurrently affected by floods due to intense precipitations: Aveiro, Estarreja, Oliveira do Bairro, Sever do Vouga, Vagos, and Mira. Besides, considering the coastal influence of this territory, there are also reports of recurring floods due to spring tides in Estarreja, Ílhavo, and Murtosa $[88,89]$.

\section{Results}

Herein, we illustrate the MINDED method for flood extent estimation through an application to the Aveiro Region study area. In order to preserve the use of free software only, all image processing tasks were performed with GRASS GIS (v7.2.2), while map compositions were made with QGIS (v2.18.15).

\subsection{Selection of Events}

Considering the lack of a long-term systematic record of floods in the Aveiro region, the selection of events was based on an indirect method. Daily precipitation data were extracted from a monitoring database portal [90], corresponding to 23 meteorological stations located inside the Vouga river catchment area (between 30 December 1979 and 12 September 2017). Maximum daily precipitation records were ranked from largest to smallest, for every meteorological station. Return periods were calculated from Equation (2), derived from a Weibull distribution (Equation (3)), where, Tx is the period expressed in number of years, $P_{x}$ is the probability of exceedance, $\mathrm{n}$ is the number of observations and $r$ is the rank number [91].

$$
\begin{gathered}
T_{x}=\frac{1}{P_{x}}, \\
P_{x}=\frac{r}{(n+1)} 100,
\end{gathered}
$$

Table A1 resumes the 50 largest daily precipitation events, providing maximum daily precipitations and maximum return periods (calculated independently for each of the 23 meteorological stations). The highest record corresponds to a return period of 32.7 years and maximum daily precipitation of $180.0 \mathrm{~mm}$. We used this list in order to search for usable couples ( $t 1$ and $t 2)$ of imagery to be processed (see Section 4.2).

\subsection{Satellite Data Selection}

In order to maintain the simplicity of this methodological application, the selection of satellite data was restricted to freely available orthorectified products of multispectral surface reflectance. Landsat Level-2 products (from Landsat 4 to 8 ) are accessible 'On-demand' (i.e., usually requiring few hours between the order and delivery of the products) in the NASA's EarthExplorer portal (https://earthexplorer.usgs.gov/). Landsat $5 \mathrm{TM}, 7 \mathrm{ETM}+$, and 8 OLI have the same spatial resolution (30 $\mathrm{m}$ in the visible, NIR and SWIR bands) and temporal resolution (16 days, that decrease if more satellites are accounted for a multitemporal analysis). Sentinel 2 Level-2A products, instead, can be downloaded from the Copernicus Open Access Hub website (https://scihub.copernicus.eu/). Sentinel 2 are acquired by the same sensor carried by a constellation of two satellites (Sentinel 2A and 2B). Sentinel 2 data have a spatial resolution that varies from $10 \mathrm{~m}$ to $60 \mathrm{~m}$ in the visible, NIR, SWIR range (10 $\mathrm{m}$ to $20 \mathrm{~m}$ for the exploited bands) and a constellation temporal resolution of 5 days at equator [92].

From the list of the 50 largest precipitation events (Table A1), we searched images matching the methodological requirements of this study, i.e., cloud-free conditions and a reasonably short time span between $t 1$ and $t 2$ (we assumed approximately 1 month prior and 15 days after each event). This process resulted in four suitable events to be analyzed (Table 5). Amongst these, only two events 
match reports of flood occurrences. This is likely the consequence of flooding not being dependent from daily precipitation only, since other factors, such as precipitation intensity, dam breach/discharges, etc. may be relevant. Besides, flood records may be incomplete, since they are more focused on recent years. Also, we observe data discontinuities from several meteorological stations, indicating that some of them did not acquire date continuously. Finally, as with most Portuguese rivers, those within the study area are densely dammed, contributing to regulate water levels during intense precipitation periods (especially during drier months).

Table 5. Selected precipitation events, available satellite images (LS-Landsat; S—Sentinel) and flood event records. For a complete list, consult Table A1.

\begin{tabular}{cccccc}
\hline Date & $\begin{array}{c}\text { Maximum Daily } \\
\text { Precipitation (mm) }\end{array}$ & $\begin{array}{c}\text { Maximum Return } \\
\text { Period (Years) }\end{array}$ & \multicolumn{2}{c}{ Available Satellite Images } & Flood Event Records \\
\cline { 4 - 5 } & 80.6 & 26.5 & LS7 (07 December 2002) & LS7 (24 January 2003) & $\begin{array}{c}\text { Estarreja, Oliveira do } \\
\text { Bairro, Vagos, Murtosa }\end{array}$ \\
\hline 19 January 2003 & 128.9 & 16.4 & $\begin{array}{c}\text { S1 (6 February 2016); LS8 } \\
\text { (5 February 2016) }\end{array}$ & LS7 (29 February 2016) & Águeda \\
\hline 13 February 2016 & 78.5 & 11.8 & LS7 (12 February 2004) & LS7 (15 March 2004) & - \\
\hline 12 March 2004 & 119.0 & 6.8 & LS7 (21 September 2009) & LS5 (15 October 2009) & - \\
\hline 7 October 2009 & & & & &
\end{tabular}

The major selectable precipitation event matching flood records occurred in 2003 (19 January 2003), with a return period of 26.5 years (the third largest of all records). The available satellite images include two Landsat 7 TM scenes, with $t 2$ being acquired 5 days after the event (RGB composites are compared in Figure 4). Records mention the floods of January 2003, which affected the municipalities of Estarreja, Mira, Murtosa, Oliveira do Bairro and Vagos (affecting infrastructures and agriculture fields in Sosa, nearby the Boco River) [88,89]. The second largest, occurred in 2016 (13 February 2016), ranking 12th, with a return period of 19.2 years. This event affected mostly the municipality of Águeda, causing multiple material damages and one mortal victim. The remaining selected events occurred in 2004 (12 March 2004) and 2009 (7 October 2009), with considerably smaller return periods and without any reports of flooding within the study area.
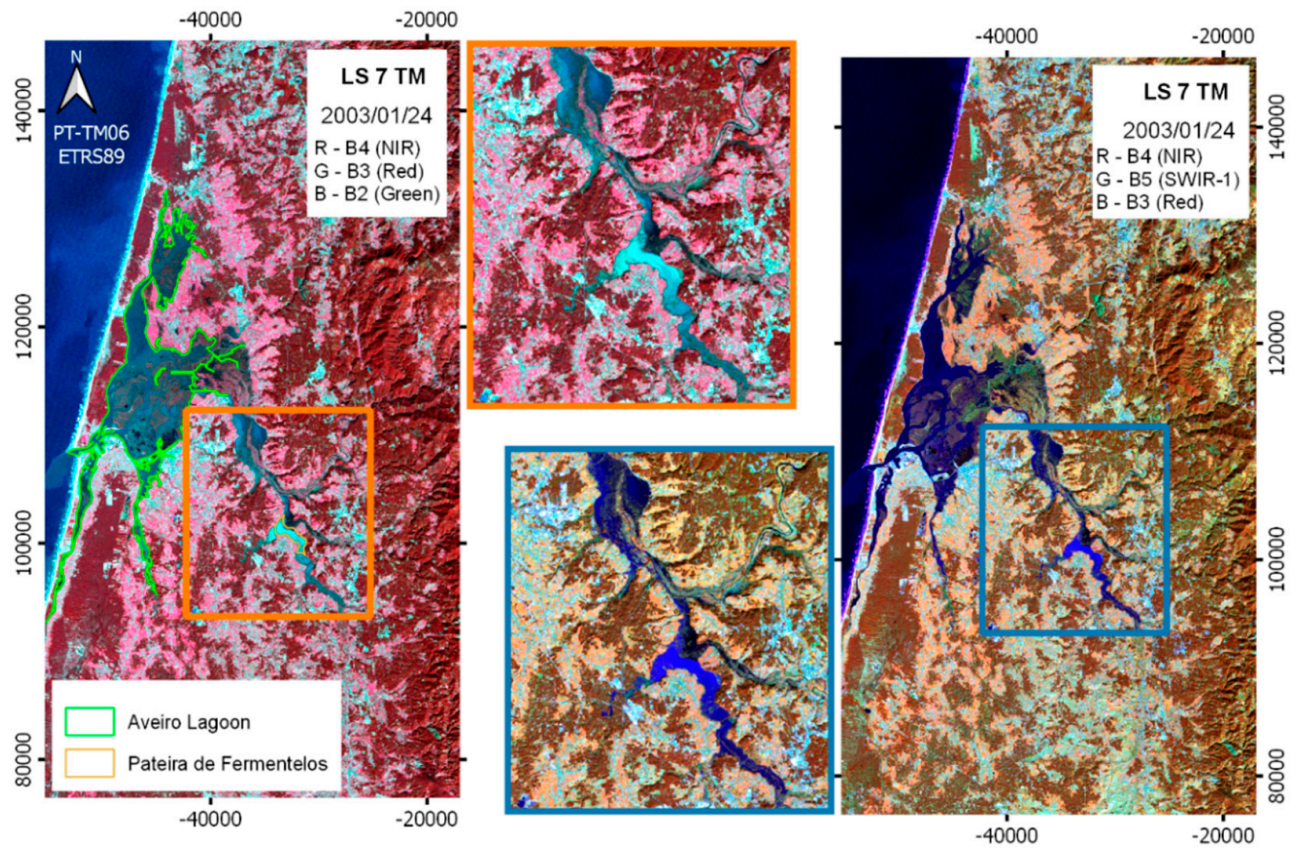

Figure 4. False-color RGB composites of Landsat 7 (LS7) TM bands, acquired 5 days after the 19/01/2003 flood event (26.5 return period). (Coordinate system: PT-TM06/ETRS89). 
Those selected events were analyzed with MINDED, using available Landsat 5, 7 and 8 data. Landsat 7 images acquired after 31 May 2003 have data gaps caused by a failure in the Scan Line Corrector (SLC). Nevertheless, we decided to include such images in our analysis by excluding the corresponding faulty pixels in both epochs ( $t 1$ and $t 2)$. The list of all available images is reported in Table A1.

\subsection{Pre-Processing}

In order to perform masking of topographic shadows using only free available data, we decided to use the ALOS World 3D-30 m (AW3D30) Global DEM provided by the Japan Aerospace Exploitation Agency (JAXA at http://www.eorc.jaxa.jp/ALOS/en/aw3d30/data/index.htm), due to its horizontal resolution and improved vertical accuracy $[93,94]$. Shaded relief maps, where produced for $t 1$ and $t 2$ (using the r.relief command of GRASSGIS).

Regarding clouds and cloud shadows, we decided to use the quality assessment bands of Landsat Level-2 products, which provides probabilities of occurrence of such features. Using the information of 'pixel_qa' band, we selected those matching the following attributes in order to extract cloud-related masks: 'Cloud Shadows', 'Snow/Ice', 'Cloud', 'Low cloud confidence', 'Medium cloud confidence' and 'High cloud confidence' [95]. Note that we assumed a conservative approach by including the lowest levels of confidence.

Topographic shadows and cloud-related masks were merged into a global mask (using GRASSGIS command r.mapcalc).

\subsection{Index Calculation and Differencing}

As introduced in Section 2, we first determined the WrI and $\Delta \mathrm{WrI}$ imagery. Then, we obtained the $\Delta \mathrm{WrI}$ frequency distribution histograms $(f)$ and corresponding first and second order derivatives (respectively $d f$ and $d 2 f$ ). Given the difference of scales between normalized and non-normalized $\Delta \mathrm{WrI}$, we used different binning ranges to obtain frequency functions, respectively based on 255 and 5000 classes. Moreover, smoothing of $f$ (by means of moving averages) was useful to aid the interpretation of $d f$ and $d 2 f$ in order to extract thresholds.

The threshold extraction procedure is exemplified in Figure 5 for $\triangle$ NDWI, $\triangle$ NDVI and $\triangle T C W$ using the same flooding event of 2003. The different shape of the $\Delta \mathrm{TCW}$ distribution (as well as the other non-normalized $\Delta \mathrm{WrI}$ ), compared to $\Delta \mathrm{NDWI}$ and $\Delta \mathrm{NDVI}$ (Figure $5 \mathrm{a}$ ), is due to the compression of scale caused by the high magnitude of the extreme values of the parameter. As the $f$ distribution does not show secondary modal values beyond the Nc mode, these $\Delta \mathrm{WrI}$ frequency functions are interpreted as being representative of the example in Figure $2 d$. For these reasons, instead of interpreting $d f$ (Figure $5 b$ ), we analyzed $d 2 f$ to obtain TL and TH (Figure $5 c$ ). Since NDVI detects water as negative values, threshold selection analysis was focused on the negative side of the $\Delta$ NDVI frequency distribution histogram, unlike the other indices. Following the theoretical premises of Figure 2d, the selection of TL corresponds to the absolute modal value of $d 2 f$, which identification was straightforward for the entire dataset under analysis. Instead, the selection of TH required further statistical processing due to a less favorable signal to noise ratio conditions caused by the lower frequency of pixels having $\Delta \mathrm{WrI}$ larger than the TH. For this reason, we performed a series of smoothing procedures by using unweighted moving averages, until finding the setup which provided the best delineation of the following local maximum (TH) of $d 2 f$.

Finally, the application of TL and TH allowed us to obtain the thematic spatial representations shown in Figure 5c. Table 6 includes the threshold list for all $\Delta \mathrm{WrI}$ and for every selected event. 


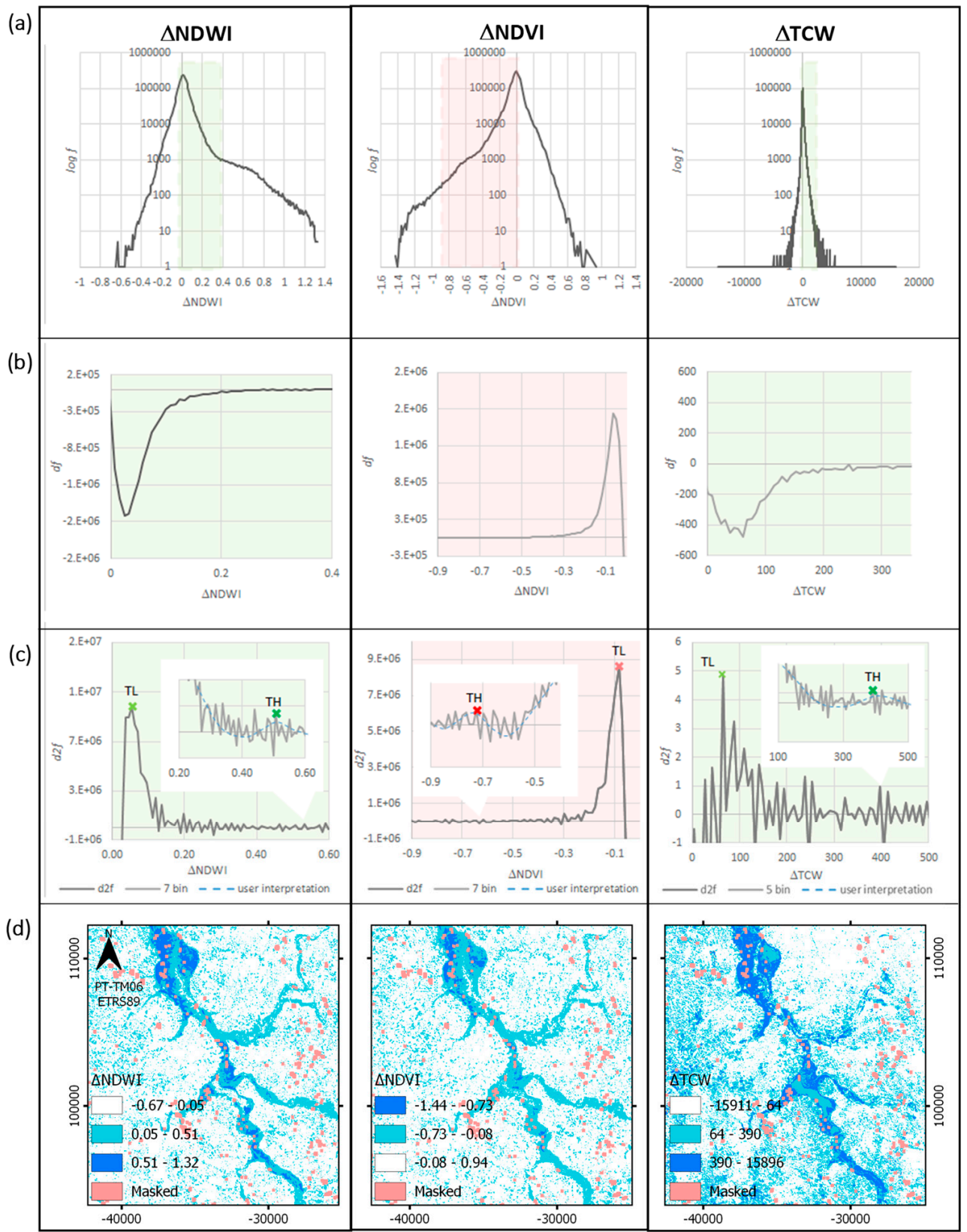

Figure 5. Examples of threshold extraction (TL and TH) analysis from $\triangle$ NDWI, $\triangle N D V I$ and $\Delta T C W$ (for the event of 2003, within the region of interest): (a) frequency distribution functions; (b) first order derivatives $(d f)$; (c) second order derivatives $(d 2 f)$; (d) spatial representation of $\Delta \mathrm{WrI}$ after thresholding (Coordinate System: PT-TM06/ETRS89).

Table 6. Thresholds of each $\Delta \mathrm{WrI}$, for every selected event.

\begin{tabular}{ccccccccc}
\hline & \multicolumn{2}{c}{2003} & \multicolumn{2}{c}{2004} & \multicolumn{2}{c}{2009} & \multicolumn{2}{c}{2016} \\
\cline { 2 - 9 } & TL & TH & TL & TH & TL & TH & TL & TH \\
\hline$\Delta$ NDWI & 0.05 & 0.51 & 0.02 & 0.32 & 0.00 & 0.58 & 0.10 & 0.42 \\
$\Delta$ MNDWI & 0.07 & 0.62 & 0.00 & 0.20 & 0.00 & 0.48 & 0.08 & 0.35 \\
$\Delta$ NDVI & -0.80 & -0.73 & -0.06 & -0.44 & -0.02 & -0.49 & -0.13 & -0.32 \\
$\Delta$ TCW & 64 & 390 & 12 & 250 & 132 & 513 & 43 & 318 \\
$\Delta$ AWEI_NS & 322 & 2604 & 138 & 2332 & 333 & 2442 & 1476 & 4566 \\
$\Delta$ AWEI_S & 388 & 1173 & 143 & 668 & 94 & 1419 & 876 & 2974 \\
\hline
\end{tabular}




\subsection{Flood Extent Estimation Results}

After the selection of the thresholds, we performed density slicing [10,41] for each $\Delta \mathrm{WrI}$, resulting in a stack of six thematic maps for each of the four events. The overall flood extent map is produced using mathematical operators that assign each pixel to pick the class that corresponds to the majority within the stack of coeval thematic classifications (i.e., at least four consistent classifications). Whenever the condition of a majority is not met, pixels are classified as 'Mixed'.

Taking the largest precipitation event (19 January 2003) as an example, we compared each $\Delta \mathrm{WrI}$ coeval thematic map (Figure 6). In every map, a noticeable concentration of LMc and HMc areas along both the Pateira de Fermentelos lagoon and the major riverbeds of the region of interest (ROI) may be observed. In particular, HMc areas are concentrated to the Northwestern part of the ROI (towards both sides of the Vouga River section). Another array of HMc areas is located towards the Northeastern side of the Pateira de Fermentelos lagoon, near the confluence with the Águeda River. As for the half-southern part of the ROI (along the Águeda river, the Cértima river and its confluence with the Pateira de Fermentelos), HMc change areas are generally detected except for $\triangle$ NDVI, which detect them as LMc. In general, with respect to maps obtained by normalized indices, those from non-normalized indices are characterized by larger extents of randomly distributed change pixels located away from fluvial areas. Table 7 summarizes the information about the extent of the coeval thematic classes obtained within the ROI from each $\Delta$ WrI, for the 2003 event. Most LMc areas are detected by $\triangle \mathrm{AWEI}$ NS and $\triangle \mathrm{TCW}$ (respectively $24.2 \%$, and $21.8 \%$ ), while most HMc areas are detected by $\triangle$ AWEI_S, $\triangle$ AWEI_S and $\triangle$ TCW (respectively 9.3\%,7.8\%, and 3.8\%). Amongst all indices, normalized indices are overall less sensitive to detect HMc areas, with $\triangle$ NDVI being the least one (1.2\% of the ROI).

Table 7. Coeval class results, obtained within the ROI from each $\Delta \mathrm{WrI}$, for the 2003 flood event.

\begin{tabular}{ccccccc}
\hline & \multicolumn{2}{c}{ Nc } & \multicolumn{2}{c}{ LMc } & \multicolumn{2}{c}{ HMc } \\
\cline { 2 - 7 } & Area (ha) & \% & Area (ha) & \% & Area (ha) & \% \\
\hline$\Delta$ NDWI & 25,138 & 75.8 & 5870 & 17.8 & 872 & 2.6 \\
$\Delta$ MNDWI & 27,369 & 82.6 & 3578 & 10.8 & 933 & 2.8 \\
$\Delta$ NDVI & 26,895 & 81.1 & 4579 & 13.8 & 404 & 1.2 \\
$\Delta$ TCW & 22,166 & 66.9 & 7238 & 21.8 & 1267 & 3.8 \\
$\Delta$ AWEI_NS & 21,255 & 64.1 & 8029 & 24.2 & 2594 & 7.8 \\
$\Delta$ AWEI_S & 24,799 & 74.8 & 3988 & 12.0 & 3092 & 9.3 \\
\hline
\end{tabular}

The Overall flood map (Figure 7a) and the Uncertainty map (Figure $7 \mathrm{~b}$ ) are obtained by a procedure based on stacking the six coeval $\Delta \mathrm{WrI}$ thematic maps (Section 2.1). We observe that the frequency of 'Mixed' pixels (9.1\% of the ROI) is smaller than the sum of the remaining classes (Nc + LMc + HMc $=87.1 \%$ ). Moreover, 'Mixed' pixels are also clearly less widespread than the randomly distributed change pixels located away from fluvial areas (Figure 7a vs. Figure 6). Larger regions of 'Mixed' pixels mostly make a rim between Nc-LMc and LMc-HMc. The quantitative uncertainty map makes it possible to perform a spatial analysis of classification consistencies. Low uncertainty values are predominant ( 0 to $2-81.9 \%$ of the ROI), whereas the highest uncertainties ( 3 to $\approx 4-0.9 \%$ of the ROI and $0.4 \%$ of the whole study area) are concentrated around areas of change, with special incidence into the major riverbeds. 


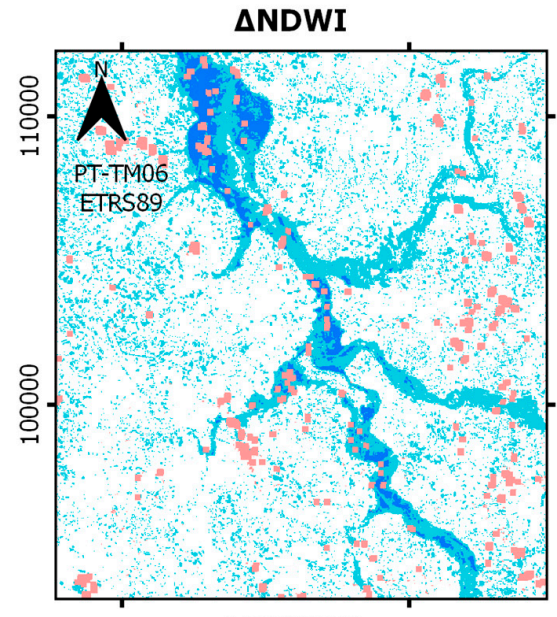

$\triangle M N D W I$
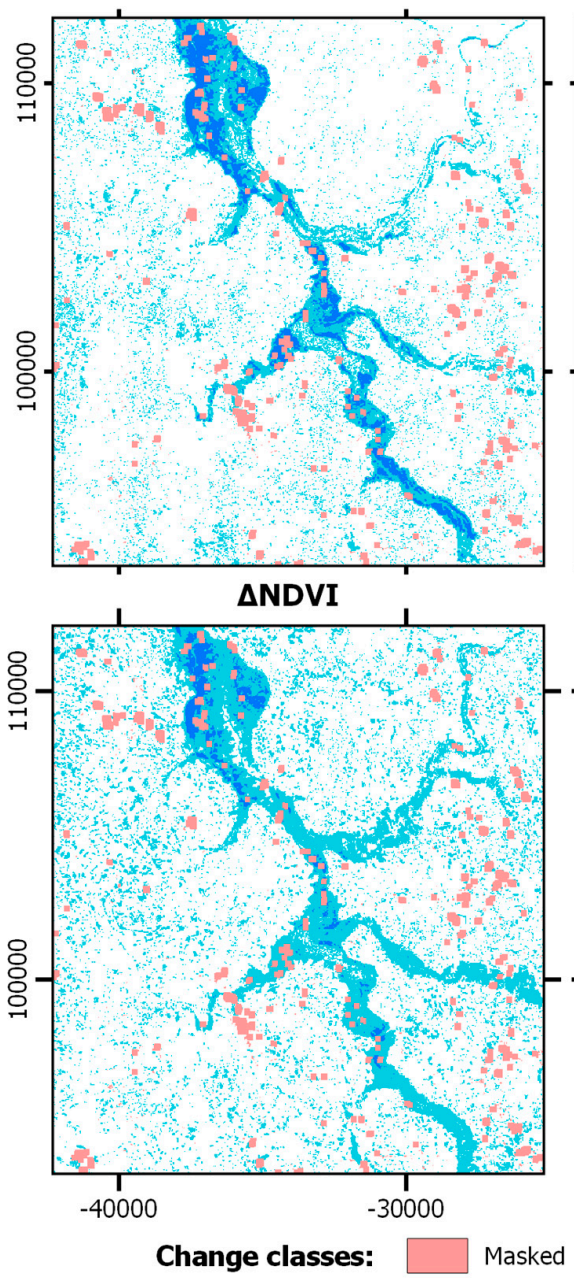

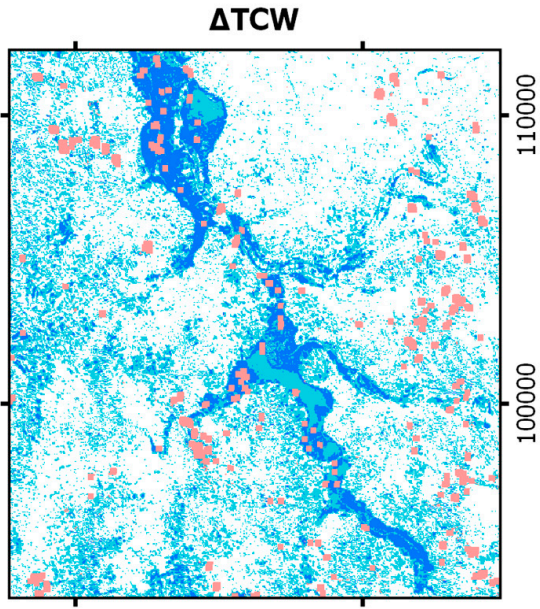

$\triangle$ AWEI_NS

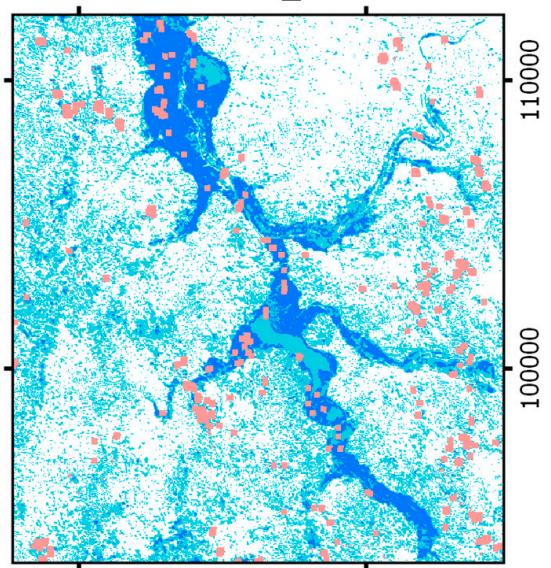

$\triangle A W E I$ S

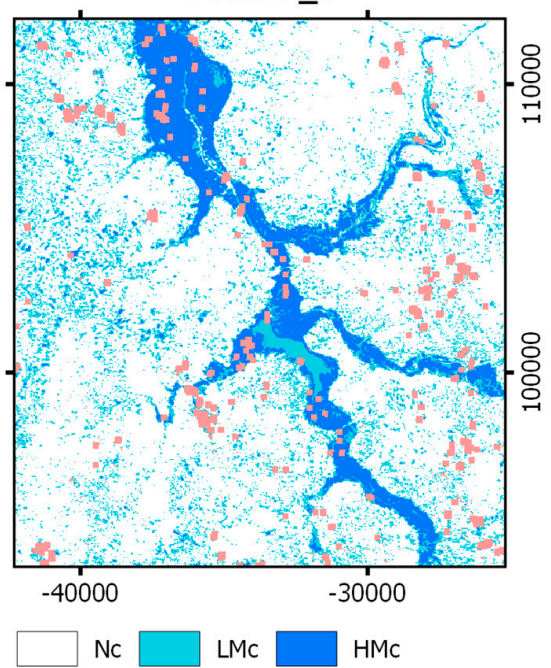

Figure 6. Coeval thematic maps for each $\Delta \mathrm{WrI}$, at the region of interest, for the event of 19 January 2003 (Coordinate System: PT-TM06/ETRS89).

Water-related Overall change maps obtained for all four selected events have been compared (Figure 8). Quantitative results are represented in Table 8. For the event of 2004, we detected almost only Nc areas. In 2009, only few LMc (4.4\%) and HMc (0.4\%) areas were detected by MINDED, most of them corresponding to saltmarshes and mudflat areas located inside the Aveiro lagoon. As for the ROI, the few LMc and HMc areas are located within the Pateira de Fermentelos lagoon. Most LMc and HMc areas that appear in the maps of Figure 8 are related to the two largest precipitation events. In 2016, 
the lower parts of the Vouga (Albergaria-a-Velha) and Antuã rivers (Estarreja) a large extent of LMc and HMc areas is mapped. Most changes are located around the Pateira de Fermentelos lagoon, along the Cértima and Águeda rivers (the second in a smaller extent), intersecting Águeda and Oliveira do Bairro municipalities. Regarding the event of 2003, which is characterized by the largest return period (26.5 years-Table 5), we detected the largest extent of change pixels, a total of 23,660 ha (corresponding to $8.2 \%$ of the whole study area). For this largest event, change areas are consistent with the records of fluvial flood occurrences (see Section 4.2) which were detected in all the reported municipalities. Once more, several change areas within the Aveiro Lagoon correspond to intertidal saltmarshes and mudflat areas.

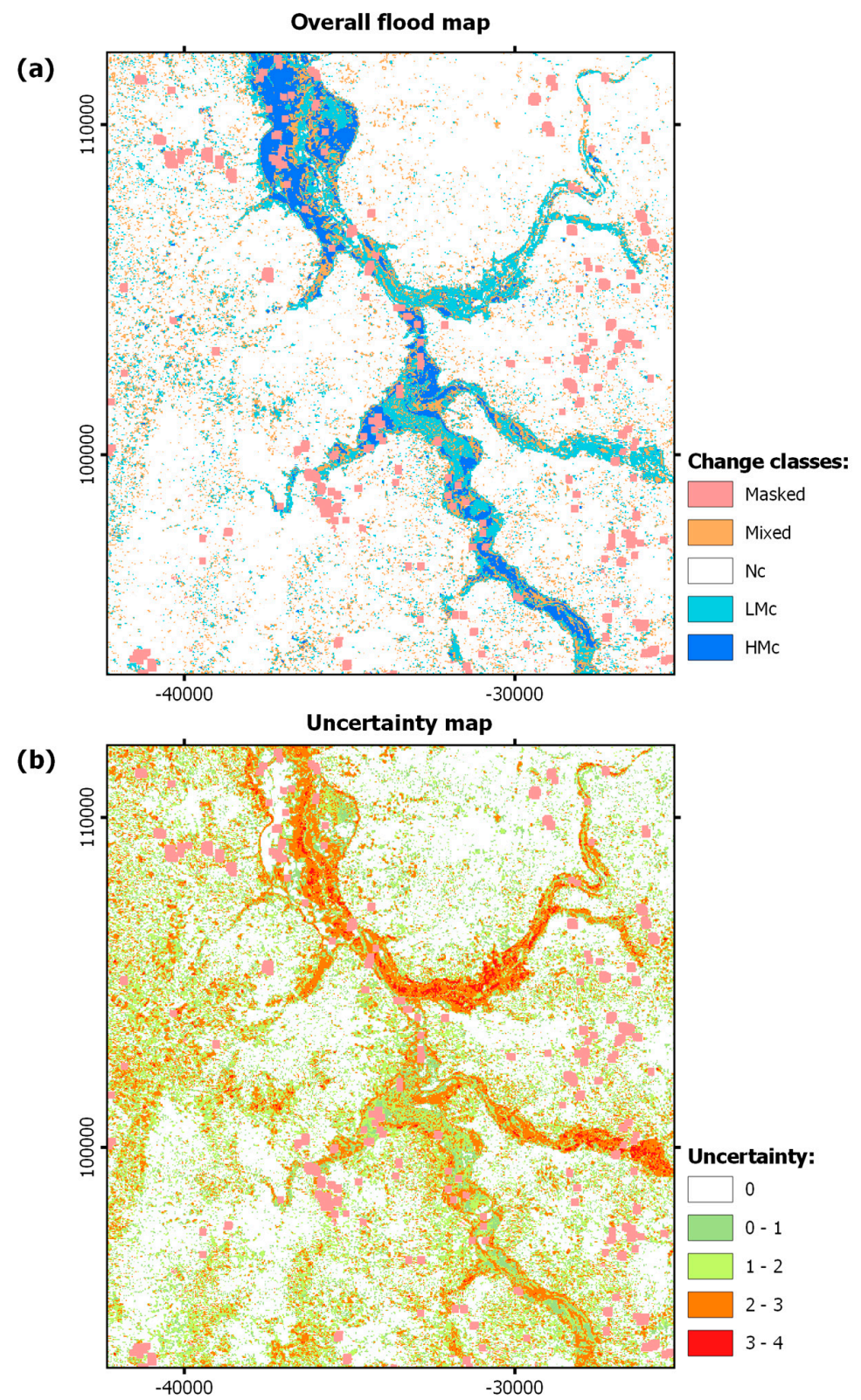

Figure 7. MINDED results for the 19 January 2003 event, at the region of interest: (a) Overall flood map; (b) Uncertainty map (Coordinate System: PT-TM06/ETRS89). 

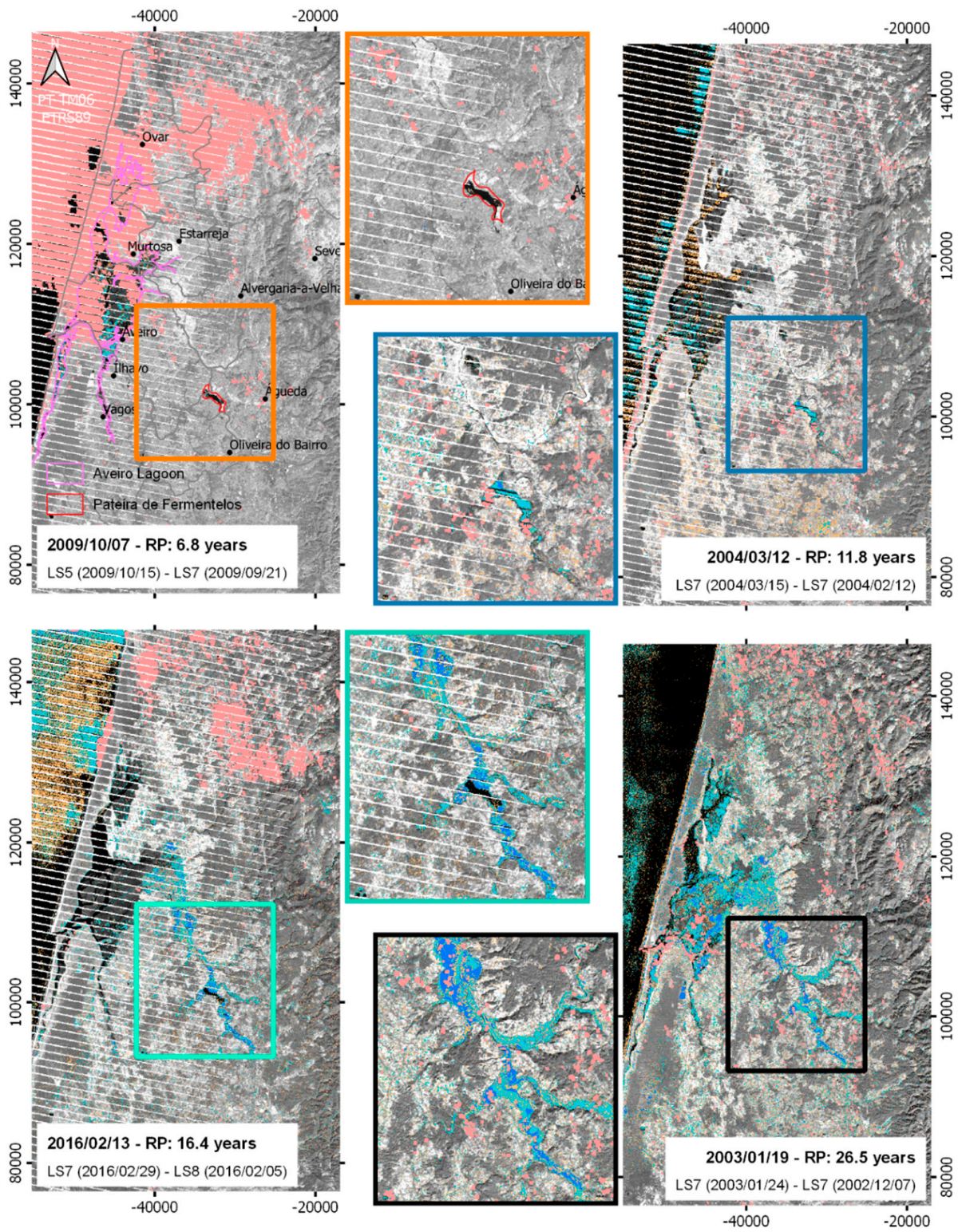

Overall flood maps $\square$ Masked $\square$ Mixed $\square$ Nc $\square$ LMc $\square$ HMc

Figure 8. Overall flood maps obtained with MINDED, for each selected event (the corresponding NIR band of $t 2$ is displayed in grayscale as the background of Nc pixels) within both the study area and ROI (Coordinate System: PT-TM06/ ETRS89).

Table 8. Overall flood map results for the whole study area in terms of extent (ha and \%) and corresponding class mean uncertainties (MU), for every selected event.

\begin{tabular}{|c|c|c|c|c|c|c|c|c|c|c|c|c|}
\hline \multirow{2}{*}{ Overall Flood Results } & \multicolumn{3}{|c|}{2003} & \multicolumn{3}{|c|}{2004} & \multicolumn{3}{|c|}{2009} & \multicolumn{3}{|c|}{2016} \\
\hline & ha & $\%$ & MU & ha & $\%$ & MU & ha & $\%$ & MU & ha & $\%$ & MU \\
\hline Nc & 229,067 & 79.5 & 0.6 & 187,508 & 65.1 & 0.4 & 24,835 & 74.9 & 1.0 & 181,247 & 62.9 & 0.8 \\
\hline LMc & 20,214 & 7.0 & 2.2 & 14,238 & 1.5 & 2.6 & 1639 & 4.4 & 2.4 & 17,399 & 6.0 & 2.7 \\
\hline HMc & 3446 & 1.2 & 1.9 & 377 & 0.1 & 2.6 & 130 & 0.4 & 2.8 & 3381 & 1.2 & 2.2 \\
\hline
\end{tabular}

\subsection{Comparison with SAR Data}

Given SAR potentialities for mapping water bodies and the environmental characteristics of the study area (i.e., an absence of complex topography, snow and dry sand surface, relevant urban areas), 
Sentinel 1 images can be considered as a reliable source of data to perform comparisons with the MINDED outputs. Hence, we compared our results with flooding maps obtained by the Hierarchical Split-Based Approach (HSBA) [30]. This is a straightforward automatic change detection method based on Sentinel-1 imagery differencing.

Considering the availability of Sentinel 1A data, the HSBA algorithm was implemented to analyze the event of 2016 (13 February 2016), using three Sentinel 1A images, one for a period before the event, and two for a period after. Thus, we selected the same reference image from 6 February 2016 (7 days before the event), and two others, one from 18 February 2016 (5 days after the event) and another from 1 March 2016 ( 1 day after the LS7 image used as $t 2,16$ days after the event) as post-event images.

Each Sentinel 1A scene was obtained in IWS (interferometric wide swath) mode, as ESA GRDH products $(20 \times 22 \mathrm{~m}$ resolution, resampled to $10 \times 10$ pixels $)$. All selected Sentinel-1A products have been acquired with the same relative orbit (125). The algorithm was applied using the following options: Lee Sigma speckle filter $(3 \times 3)$, SRTM 1 arc sec geocoding, 5 minimum levels for HSBA, 2.4 Ashman coefficient, a minimum number of 1.000 pixels for the image tiles to process, and by considering to eliminate objects below 10 pixels.

Wind conditions during the acquisition affect water surface roughness, and therefore, the accuracy of both water surface and flood extent mapping. According to meteorological data of 'Estrada' and 'Tentugal' stations [90], the wind speed at the acquisition times of all the considered images was less than $2.0 \mathrm{~m} / \mathrm{s}$, which has no effects in inland waters [96].

The comparison between MINDED and HSBA results for the event of 2016 is illustrated in Figure 9.

From the analysis of Figure 9b,c, it is possible to observe that the extent of flooded areas detected by the HSBA algorithm reduced over time (i.e., from 18 February 2016 to 1 March 2016), with particular incidence to North and West of the Pateira de Fermentelos lagoon (along the Águeda and Vouga rivers). This is confirmed by the multi-temporal Sentinel 1A RGB composite (Figure 9d), which highlights in purple those areas flooded by 18 February 2016, but recovered toward the initial conditions on 1 March 2016. Those areas still flooded by 1 March 2016 (dark blue) are mostly concentrated to Southwest of the Pateira de Fermentelos lagoon (along the Cértima River).

A quantitative pixel location comparison of MINDED is presented within the form of confusion matrixes (Table 9), using MINDED as reference data (although neither method provides ground truth reference). For comparison purposes, HSBA results were reprojected and resampled to the same grid of MINDED (i.e., the resolution of Landsat images, $30 \times 30 \mathrm{~m}$ ), using bilinear interpolation. Class accuracies, commission errors (i.e., overestimation), omission errors (i.e., underestimation) and overall accuracies are provided.

Table 9. Confusion matrix between results of MINDED and HSBA methods, analyzed in terms of No Change (Nc) and Flooded areas (LMc + HMc), for the event of 13 February 2016, within the region of interest.

\begin{tabular}{|c|c|c|c|c|c|}
\hline & & \multicolumn{4}{|c|}{ MINDED-LS7 29 February 2016} \\
\hline & & $\mathrm{Nc}$ & Change (LMc + HMc) & Total & Commission Error (\%) \\
\hline & Non-Flooded & 273,516 & 43,198 & 316,714 & 13.64 \\
\hline & Flooded & 245 & 4688 & 4933 & 4.97 \\
\hline HSBA-S1A & Total & 273,761 & 47,886 & 321,647 & \\
\hline \multirow[t]{5}{*}{$18 / 02 / 2016$} & Class agreement $(\%)$ & 99.91 & 9.79 & & \\
\hline & Omission error (\%) & 0.09 & 90.21 & & \\
\hline & Overall agreement (\%) & \multicolumn{4}{|c|}{86.49} \\
\hline & Non-Flooded & 273,685 & 46,231 & 319,916 & 14.45 \\
\hline & Flooded & 76 & 1655 & 1731 & 4.39 \\
\hline HSBA-S1A & Total & 273,761 & 47,886 & 321,647 & \\
\hline \multirow[t]{3}{*}{ 01/03/2016 } & Class agreement $(\%)$ & 99.97 & 3.46 & & \\
\hline & Omission error (\%) & 0.03 & 96.54 & & \\
\hline & Overall agreement $(\%)$ & \multicolumn{4}{|c|}{85.60} \\
\hline
\end{tabular}



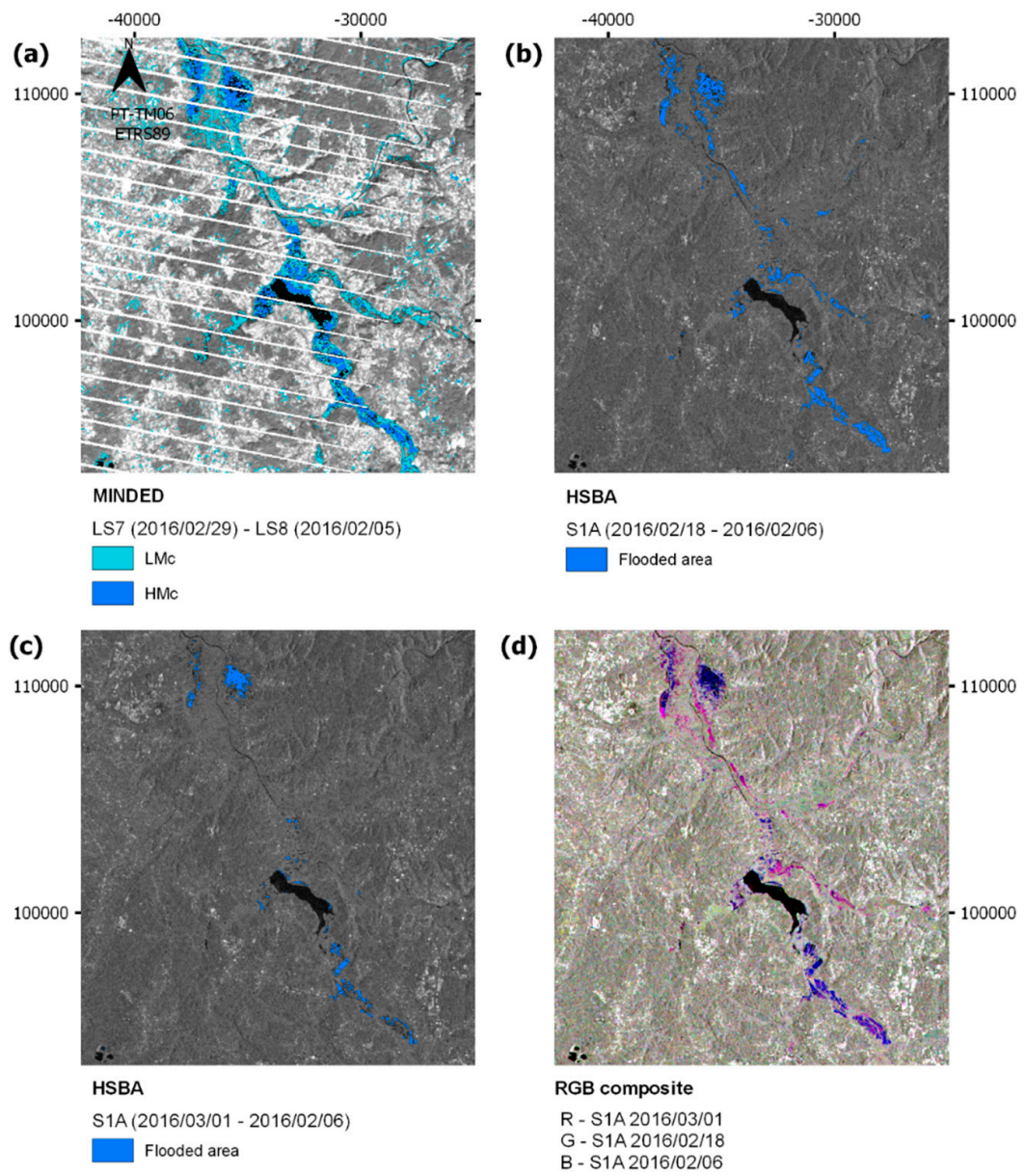

Figure 9. Comparison of flooded areas results for the 2016 event (13 February 2016) within the ROI, obtained with: (a) MINDED (NIR band of LS7 29 February 2016 in the background); (b,c) the HSBA algorithm-considering two different post-event images (S1A IW GRDH from 18 February 2016 and 1 March 2016 respectively, represented in the backgrounds); (d) False color RGB composite: R-S1A obtained 16 days after the event (1 March 2016), G-S1A obtained 5 days after the event (18 February 2016), B-S1A reference image 7 days prior to the event (6 February 2016) (Coordinate System: PT-TM06/ETRS89).

Despite the temporal proximity between the post-event images Landsat 7 (29 February 2016) and Sentinel 1A (1 March 2016), the match between MINDED change classifications (i.e., LMc + HMc) and HSBA flooded areas is only 1635 pixels (149 ha), corresponding to a class agreement of $3.46 \%$. Instead, the match with the Sentinel 1A image closer to the flood event (18 February 2016) is 4688 pixels (422 ha), corresponding to a class agreement of $9.79 \%$. In both periods, HSBA underestimates flooded areas in comparison to MINDED, which is more noticeable for 1 March 2016 (omission error of 97\%), and less for 18 February 2016 (omission error of 90\%). The commission errors of flooded areas for both HSBA periods are significantly low, 4.97\% for 18 February 2016 and 4.39\% for 1 March 2016, resulting from conflicting classifications of Non-Flooded (HSBA) and Change areas (MINDED). Regardless of the date of post-event HSBA images, we verify overall agreement levels around $86 \%$. The clear majority of concordant Non-flooded-Nc classifications influences the high overall agreement levels.

\section{Discussion}

We performed a multi-index differencing method (MINDED) to detect flooded areas aimed at improving the robustness of single-index approaches. This benefits from the sensitivities of individual 
indices for detecting water with different characteristics, to mitigate their specific limitations, and to assess the consistency among flood detection results within the so-called Overall flood map.

In digital change detection approaches, thresholds control the results of image differencing, which may be a critical undertaking when no ground truth data is available [35]. In practice, missing ground truth is the typical condition when analyzing archive data, and in particular when studying extreme events like floods, for which systematic collection of field data may be problematic. For these reasons, MINDED includes an expedited procedure aimed at reducing subjectivity for thresholds selection. The procedure is based on the analysis of the frequency distribution of water-related index differencing $(\Delta \mathrm{WrI})$ data, as well as the corresponding first and second order derivatives. Different thresholds may be selected to discriminate between No change $(\mathrm{Nc})$ areas and different types of change, based on both magnitude and sign of $\Delta \mathrm{WrI}$ values. Nc areas are expected to include any kind of permanently dry surfaces, as well as permanent water bodies and stable wet/saturated surfaces. High Magnitude change $(\mathrm{HMc})$ areas represent a complete change of state from dry land to water surfaces. Low Magnitude change (LMc) areas may include different conditions of subtle change like either areas changing from dry to wet/saturated, or from wet/saturated to water surfaces. Moreover, when post-event ( $t 2)$ images are acquired several days after the flood, LMc may also include areas which were initially flooded, then underwent the process of recovering toward their original status. For this reason, we consider that MINDED widens the period in which to obtain usable images to extract maximum flood extents. This is particularly relevant for optical satellite imagery, due to their heavy dependence on cloud-free conditions, which tend to be less frequent immediately after heavy precipitation periods. The multi-index approach also makes it possible to extract a 'Mixed' class resulting from a majority analysis implemented within MINDED, as well as an Uncertainty map (Equation (1)) which quantitatively represents the spatial distribution of coherence among the different WrI results. The determination of uncertainty is also based on accuracies known from the literature (Table 4), which are used as weighting factors. As a consequence, MINDED incorporates the assumed performance of single WrI, even though such accuracies may have been obtained by different methods, assumptions, and sensors, as well as environmental conditions.

As for the implementation of MINDED in the study area, further conclusions may be drawn. Regarding the selection of events to perform the analysis, it is necessary to acknowledge the importance of acquisition time for both pre- and post-event images (respectively $t 1$ and $t 2$ ). When working with archive imagery related to past events, for which details about spatiotemporal flooding evolution are unknown, the reference image $t 1$ may represent already altered conditions, due to either previous flooding or high water discharge levels. In these cases, the outputs of MINDED will result in underestimation of the overall flooded area. As for $t 2$, the detection capabilities could vary depending on surface permeability, drainage behavior, and post-event anthropic management, which may limit the available time for usable post-event image acquisition. This is particularly relevant for the 13/02/2016 flood, which was studied with a Landsat (LS) 7 image acquired 16 days after the event. In this case, MINDED was able to detect tracks of floods in naturalized areas (e.g., mostly HMc areas nearby the Pateira de Fermentelos lagoon), even though only LMc areas were detected in the Águeda city center, where several streets were reported to be previously inundated. It is important to highlight that the effects of flooding on impervious surfaces, like those of urban areas, are ephemeral and few hours/days may be enough to return to the pre-event surface reflectivity conditions. Thus, we can expect the more $t 2$ is acquired later than the event, the lower is the accuracy of MINDED to map the maximum flood extent. Moreover, it is expected to observe a progressive transition from HMc to LMc classes. MINDED cannot solve these issues related to the dynamics of post-flood processes, without the integration of ground truths and/or ancillary data.

As a general condition, flood water characteristics may affect the results obtained by indices based on different wavelength ranges of the electromagnetic spectrum (e.g., NIR or SWIR [43,49,97]). This issue can be relevant for those events lacking information collected in the field (as the ones considered within this paper). Nevertheless, concerning the 2003 event, no relevant differences may 
be identified between the post-event ( $t 2)$ NIR and SWIR bands (Figure 4). Such similarities are consequently reflected in $\triangle$ MNDWI and $\triangle$ NDWI results (Table 7). In this case, the characteristics of flood water produced similar effects on both the NIR and SWIR bands, which can be interpreted as an indicator of low turbidity. In fact, the $t 2$ image was acquired 5 days after the flood event, allowing time for sedimentation to take place in slow-moving or standing water areas. Among all indices, $\triangle$ NDVI was the one detecting fewest HMc areas, confirming its weaker capabilities for recognizing water surfaces [7,39].

Regarding the statistics of the $\Delta \mathrm{WrI}$, when using different sensors for $t 1$ and $t 2$, we can expect to observe the occurrence of non-zero centered modal values. This should not be interpreted as a shortcoming since we can still assume the whole distribution, as well as the Nc condition, to be centered with the main modal value. This is verified for the 2009 and 2016 events, for which, considering the limited availability of cloud-free images during the flood periods, we decided to use different sensors for $t 1$ and $t 2$. The width of the "bell" shape of each histogram is expected to be input-data related and variable according to the distribution of both $\mathrm{Nc}$ and LMc/HMc areas, spatial and radiometric co-registration between $t 1$ and $t 2$ images, and natural time-depending changes of features (e.g., phenology changes in natural or agricultural areas). However, other sudden changes rather than flooding may also occur, which could be detected as false alarms (e.g., land cover conversions from agricultural practices, effects of fires). The latest represent intrinsic errors of any image-differencing methods, such as MINDED, which nonetheless may be recognized if such changes occur in places falling out of potentially floodable areas (e.g., by analyzing DEM).

Considering that neither of the analyzed events resulted in an ideal multi-modal histogram (Figure 2c), in order to extract the thresholds, we could not use the first order derivative $(d f)$, so we analyzed the second order derivative $(d 2 f)$ instead. While the extraction of TL, between Nc and LMc, was a straightforward procedure, the extraction of $\mathrm{TH}$, between LMc and HMc, required further statistical processing aimed at improving the signal-to-noise ratio in the considered $\Delta W r I$ range. This last task is more prone to user-subjectivity, so TH should be more reasonably considered as a range of values, which spatial effects have to be verified at map scale. Being a typical expert-dependent analysis, this segment of MINDED may be hardly implemented as a fully automatic tool procedure.

An advantage of MINDED, resulting from the approach of combining results from different WrI, is the possibility to recognize eventually erratic classifications from a certain index in respect to the others. As observed for the 2003 event, all the $\Delta$ WrI maps are characterized by apparently random distributed change pixels located away from fluvial areas (Figure 6). In a single-index flood detection approach, these pixels represent a false alarm condition which reduces the quality of the flooding map. This is particularly relevant for the non-normalized $\Delta \mathrm{WrI}$ maps, which may result from ineffective cloud masking. Also, higher sensitivities to terrain shadowing caused by local relief (Table 2) may produce similar effects, due to rough masking from global-scale DEM. A more detailed analysis of such areas highlights the fact that the spatial distributions of such pixels are mainly non-overlapping amongst the $\Delta$ WrI maps. As a consequence, the process of stacking implemented within MINDED efficiently handles these false alarms by classifying most of them as Nc, or 'Mixed' in a smaller degree (e.g., 9.3\% of the ROI for the 2003 event-Figure 7). This observation highlights the benefit of MINDED approach with respect to the standard single-index alternatives. The 'Mixed' class is mostly located nearby the transition areas between Nc-LMc and LMc-HMc, suggesting that they result from the occurrence of subtle changes which are differently recognized by each WrI. Furthermore, it also shows that the combined results from every $\Delta \mathrm{WrI}$ are each other consistent. Another indication of the effectiveness of MINDED is the analysis of the spatial distribution of uncertainty. Highest uncertainty values are concentrated around the major riverbeds and areas of change, and their frequency is low ( $\rho=3$ to $\approx 4$ $-0.4 \%$ of the study area). This suggests that, even though every WrI may provide different results about change, MINDED integrates these results giving a more robust representation of changes.

As expected, we observed larger extents of flooded areas with higher return period events. However, in some cases (2009, 2004 and 2003), several intertidal areas were classified as being flooded 
(mostly as LMc). This is a consequence of differences of tidal states between $t 1$ and $t 2$, meaning that t1 image likely was acquired during lower tide. Besides, we have to assume that MINDED might detect false alarms within permanent water bodies, such as the Pateira de Fermentelos lagoon, due to variations of water thickness/composition or floating debris/vegetation which might be classified as LMc or even HMc areas.

Regarding the comparison between MINDED and HSBA methods, results show that the location of Flooded and HMc classes areas is coherent. MINDED is more sensitive to detect tracks from recent flood events, particularly in LMc areas, which implies detection of larger flooded areas. On the other hand, despite the apparent improved spatial resolution of Sentinel 1A imagery (which is not directly comparable with the spatial resolution of optical data [98]), the HSBA algorithm seems to be less sensitive to discriminate between water 'saturated' areas and drier surfaces during the days following a flood event (resulting in higher commission errors). We consider that the low agreement level between Change and Flooded classes (Table 9), is likely related to the unavailability of Sentinel 1 images acquired during the flood event (or immediately after), as well as to the HSBA procedure which eliminates change clusters smaller than 10 pixels.

\section{Conclusions}

This study presents an innovative method based on the integration of change-detection concepts which are known from the literature. MINDED makes it possible to detect the extent of past and future flood events, combining multiple water-related indices derived from optical satellite data within a change detection approach, and benefiting from long-term image catalogs.

The method implements image differencing and provides a consistent procedure to analyze the frequency distribution of water-related indices for the extraction of different thresholds depending on the magnitude of changes, as a reproducible alternative to ground truthing. Then, types of change are discriminated considering the sign of difference and applying density slicing based on thresholds.

High magnitude changes include surfaces changing from 'dry' to 'flooded' state, while low magnitude changes correspond to surfaces changing from 'dry' to 'saturated', or 'saturated' to 'flooded' states. Unchanged areas do not discriminate between permanent water bodies and permanent dry surfaces, which is not a limitation for flood hazard analysis. By integrating different water-related indices with different sensitivities to water characteristics, and considering the agreement among the resulting classifications, the method is capable of obtaining both an Overall flood map and an Uncertainty map, estimating uncertainty bounds for flooded areas. This approach increases the robustness of results, particularly in the transition areas between flooded and non-flooded surfaces, as well as where randomly distributed changes not related to water may occur. Moreover, the possibility of analyzing flood events by comparing imagery acquired by different sensors may help to widen the temporal window for obtaining suitable optical satellite images. For these reasons, we consider MINDED being a new valid method to be integrated along with others, including SAR-based approaches (e.g., data-fusion methods), to obtain the best representation of flooded areas.

The performance of MINDED was tested with an application to a study area in Northwestern Portugal, using Landsat imagery to perform flood detection analyses for several events. The results are consistent with known historical flood records. When processing images acquired several days after a triggering precipitation event, MINDED showed capability of detecting tracks of floods both in naturalized and agricultural areas.

Since no ground truth data was available, we compared results from the same event with those obtained by processing multi-date post-event Sentinel-1A scenes using the Hierarchical Split-Based Approach algorithm. The best agreement between methods was obtained by processing the earliest post-event Sentinel-1A image, supporting the idea that MINDED provides a close representation of the maximum flood extent.

The current implementation of MINDED has the potential for automatization improvement, which would contribute to its use as a more expedite method for operational purposes. Further developments 
of MINDED should be tested in other regions and contexts, as well as by integrating more water-related indices and a different number of indices. Moreover, there is potential to implement MINDED using data obtained from other sensors, including improved spatial resolution alternatives (e.g., Sentinel-2), without requiring relevant adjustments to the procedures, still providing an evaluation of uncertainty. Finally, we highlight that the threshold selection procedure developed in this paper, when applied to either other indices or data, has the potential to be applied to change detection studies other than flooding.

Author Contributions: Conceptualization, E.R.O., L.D. and F.L.A.; Data curation, E.R.O.; Formal analysis, E.R.O. and L.D.; Funding acquisition, L.D. and F.L.A.; Investigation, E.R.O. and L.D.; Methodology, E.R.O. and L.D.; Resources, F.L.A.; Software, E.R.O. and L.D.; Supervision, L.D. and F.L.A.; Validation, L.C. and L.G.P.; Visualization, E.R.O. and L.D.; Writing—original draft, E.R.O. and L.D.; Writing—review \& editing, E.R.O., L.D., L.C., L.G.P. and F.L.A.

Funding: Thanks are due for the financial support to CESAM (UID/AMB/50017/2019), to FCT/MCTES through national funds, the co-funding by the FEDER, within the PT2020 Partnership Agreement and Compete 2020, and the "Piano di Ateneo di Sostegno alla Ricerca 2018 - University of Siena (L. Disperati). The Ph.D. grant SFRH/BD/104663/2014 (E.R. Oliveira) is also acknowledged.

Acknowledgments: The authors thank Ramona Pelich from LIST, for presenting the Hazard Flood Mapping algorithm and the GPOD service. The authors also thank the reviewers, who definitely helped to improve the final contents of this paper.

Conflicts of Interest: The authors declare no conflict of interest.

\section{Appendix A}

Table A1. Fifty largest precipitation events, from 23 meteorological stations located in the Vouga River watershed (between 1979/12/30 and 2017/09/12); Corresponding availability of satellite images: LS-Landsat; S-Sentinel; This table is ordered according to the maximum return period (descending).

\begin{tabular}{|c|c|c|c|c|c|}
\hline \multirow{2}{*}{ Date } & \multirow{2}{*}{$\begin{array}{c}\text { Maximum Daily } \\
\text { Precipitation (mm) }\end{array}$} & \multirow{2}{*}{$\begin{array}{l}\text { Maximum Return } \\
\text { Period (Years) }\end{array}$} & \multicolumn{2}{|c|}{ Available Satellite Images } & \multirow{2}{*}{ Flood Event Records $[88,89]$} \\
\hline & & & $t 1$ & $t 2$ & \\
\hline 1995/12/25 & 180.0 & 32.7 & - & - & $\begin{array}{c}\text { Agueda, Albergaria-a-Velha, } \\
\text { Aveiro, Murtosa }\end{array}$ \\
\hline $2007 / 06 / 14$ & 85.0 & 29.3 & LS5 (2007/06/04) & $\operatorname{LS5}(2007 / 06 / 20)^{*}$ & Ovar \\
\hline \#2003/01/19 & 80.6 & 26.5 & LS7 (2002/12/07) & LS7 (2003/01/24) & $\begin{array}{c}\text { Estarreja, Oliveira do Bairro, } \\
\text { Vagos, Murtosa }\end{array}$ \\
\hline $2008 / 04 / 10$ & 96.1 & 24.9 & - & LS7 $(2008 / 04 / 11 *)$ & $\begin{array}{l}\text { Estarreja, Murtosa, Mira, } \\
\text { Vagos, Olveira do Bairro }\end{array}$ \\
\hline $1993 / 10 / 09$ & 124.9 & 24.2 & - & - & - \\
\hline $1995 / 12 / 26$ & 114.5 & 23.6 & - & - & $\begin{array}{c}\text { Águeda, Albergaria-a-Velha, } \\
\text { Aveiro, Murtosa }\end{array}$ \\
\hline $1983 / 11 / 22$ & 97.0 & 23.4 & - & - & - \\
\hline 1985/02/09 & 120.0 & 23.1 & - & - & - \\
\hline 2004/12/01 & 90.0 & 22.9 & LS7 (2004/11/26) & LS7 $(2004 / 12 / 12 *)$ & - \\
\hline 1989/12/21 & 120.0 & 19.8 & - & - & - \\
\hline $2001 / 01 / 27$ & 150.1 & 19.6 & - & $\operatorname{LS7}(2001 / 02 / 03)^{*}$ & $\begin{array}{l}\text { Albergaria-a-Velha, Aveiro, } \\
\text { Estarreja, ílhavo, Sever do } \\
\text { Vouga, Vagos, Mira, Murtosa }\end{array}$ \\
\hline \#2016/02/13 & 128.9 & 16.4 & $\begin{array}{l}\text { S1 (2016/02/06); } \\
\text { LS8 (2016/02/05) }\end{array}$ & LS7 (2016/02/29) & Águeda \\
\hline $1984 / 10 / 19$ & 121.0 & 16.4 & - & - & - \\
\hline $1998 / 09 / 28$ & 85.0 & 14.6 & - & - & Águeda, Vagos \\
\hline $2003 / 01 / 03$ & 98.8 & 12.4 & - & - & - \\
\hline $2015 / 09 / 16$ & 129.4 & 12.1 & $\begin{array}{c}\text { LS7 }(2015 / 09 / 06) ; \\
\text { LS8 }\left(2015 / 09 / 14{ }^{*}\right) ; \\
\text { S1A }(2015 / 09 / 10 \\
2015 / 09 / 15)\end{array}$ & $\begin{array}{c}\text { LS7 }(2015 / 09 / 22 *) ; \text { LS8 } \\
(2015 / 09 / 30 *) ; \text { S1 } \\
(2015 / 09 / 16)\end{array}$ & - \\
\hline$\# 2004 / 03 / 12$ & 78.5 & 11.8 & LS7 (2004/02/12) & LS7 (2004/03/15) & - \\
\hline 1996/02/06 & 125.7 & 11.8 & - & - & Murtosa \\
\hline 1980/11/12 & 85.5 & 11.5 & - & - & - \\
\hline $2006 / 11 / 24$ & 96.1 & 11.4 & - & - & Estarreja, Ílhavo \\
\hline 2016/01/04 & 133.3 & 9.8 & $\begin{array}{l}\text { LS7 }\left(2015 / 12 / 27^{*}\right) \\
\text { S1 (2016/01/02); } \\
\text { S2 (2015/12/22) }\end{array}$ & $\begin{array}{l}\text { S1A (2016/01/08); S2 } \\
\quad\left(2016 / 01 / 11^{*}\right)\end{array}$ & Águeda \\
\hline 1994/01/06 & 116.1 & 9.8 & - & - & Águeda, Murtosa \\
\hline 1982/11/07 & 73.2 & 9.8 & - & - & - \\
\hline 1996/05/18 & 67.0 & 9.0 & - & - & Murtosa \\
\hline $2005 / 12 / 02$ & 111.3 & 8.8 & LS7 (2005/11/29) & LS7 (2005/12/15) & - \\
\hline $2008 / 04 / 08$ & 93.5 & 8.3 & - & LS7 (2008/04/11*) & 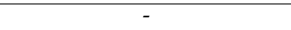 \\
\hline 1993/09/17 & 99.5 & 8.1 & - & - & - \\
\hline 1986/11/11 & 73.5 & 7.9 & - & - & - \\
\hline
\end{tabular}


Table A1. Cont.

\begin{tabular}{|c|c|c|c|c|c|}
\hline \multirow{2}{*}{ Date } & \multirow{2}{*}{$\begin{array}{c}\text { Maximum Daily } \\
\text { Precipitation (mm) }\end{array}$} & \multirow{2}{*}{$\begin{array}{l}\text { Maximum Return } \\
\text { Period (Years) }\end{array}$} & \multicolumn{2}{|c|}{ Available Satellite Images } & \multirow{2}{*}{ Flood Event Records $[88,89]$} \\
\hline & & & $t 1$ & $t 2$ & \\
\hline $1983 / 04 / 22$ & 110.0 & 7.9 & - & - & - \\
\hline 1984/11/16 & 117.0 & 7.8 & - & - & - \\
\hline $1991 / 03 / 06$ & 82.5 & 7.8 & - & - & - \\
\hline $2005 / 10 / 30$ & 80.0 & 7.7 & - & - & - \\
\hline $2003 / 08 / 29$ & 71.5 & 7.3 & - & - & - \\
\hline$\# 2009 / 10 / 07$ & 119.0 & 6.8 & LS7 (2009/09/21) & LS5 (2009/10/15) & - \\
\hline $2001 / 02 / 06$ & 73.3 & 6.6 & - & - & Ovar \\
\hline $1989 / 02 / 26$ & 87.5 & 6.6 & - & - & - \\
\hline $1987 / 09 / 26$ & 99.0 & 6.5 & - & - & - \\
\hline 1997/01/09 & 108.7 & 6.5 & - & - & Murtosa \\
\hline $2002 / 10 / 01$ & 67.1 & 6.2 & - & - & Mira \\
\hline 1992/01/08 & 67.0 & 6.0 & - & - & - \\
\hline 2009/12/07 & 73.2 & 5.9 & - & - & - \\
\hline 1994/10/05 & 63.3 & 5.9 & - & - & Ovar \\
\hline $2002 / 11 / 19$ & 73.0 & 5.9 & - & - & - \\
\hline $2004 / 10 / 27$ & 67.3 & 5.7 & - & - & - \\
\hline 2006/12/08 & 125.9 & 5.4 & LS5 (2006/10/12) & - & - \\
\hline 1996/01/09 & 66.4 & 5.0 & - & - & Murtosa \\
\hline $1988 / 01 / 25$ & 80.0 & 5.0 & - & - & - \\
\hline 2015/01/31 & 127.8 & 4.9 & $\begin{array}{c}\text { LS8 (2015/01/01); } \\
\text { S1(2015/01/30; 2015/01/31) }\end{array}$ & $\begin{array}{c}\text { LS7 }(2015 / 02 / 10)^{*} ; \text { LS8 } \\
(2015 / 02 / 18)\end{array}$ & - \\
\hline $1997 / 12 / 22$ & 77.5 & 4.9 & - & - & Murtosa \\
\hline $2009 / 10 / 22$ & 63.9 & 4.7 & - & - & - \\
\hline
\end{tabular}

\# Selected precipitation event, * Significant cloud percentage ( $>15 \%$ of the overall scene).

\section{References}

1. EEA. Mapping the Impacts of Recent Natural Disasters and Technological Accidents in Europe-An Overview of the Last Decade; European Environment Agency: Copenhagen, Denmark, 2010.

2. Liu, C. Analysis of Sentinel-1 SAR Data for Mapping Standing Water in the Twente Region. Ph.D. Thesis, University of Twente, Enschede, The Netherlands, 2016.

3. Nardi, F.; Annis, A.; Di Baldassarre, G.; Vivoni, E.R.; Grimaldi, S. GFPLAIN 250 m, a global high-resolution dataset of Earth's floodplains. Sci. Data 2019, 6, 180309. [CrossRef] [PubMed]

4. Pekel, J.; Cottam, A.; Gorelick, N.; Belward, A.S. High-resolution mapping of global surface water and its long-term changes. Nature 2016, 540, 418-422. [CrossRef] [PubMed]

5. Allen, G.H.; Pavelsky, T.M. Global extent of rivers and streams. Science 2018, 361, 585-588. [CrossRef] [PubMed]

6. Ward, P.J.; Jongman, B.; Salamon, P.; Simpson, A.; Bates, P.; De Groeve, T.; Muis, S.; De Perez, E.C.; Rudari, R.; Trigg, M.A.; et al. Usefulness and limitations of global flood risk models. Nature 2015, 5, 712-715. [CrossRef]

7. McFeeters, S.K. The use of the Normalized Difference Water Index (NDWI) in the delineation of open water features. Int. J. Remote Sens. 1996, 17, 1425-1432. [CrossRef]

8. Xie, H.; Luo, X.; Xu, X.; Pan, H.; Tong, X. Evaluation of Landsat 8 OLI imagery for unsupervised inland water extraction. Int. J. Remote Sens. 2016, 37, 1826-1844. [CrossRef]

9. Lillesand, T.M.; Kiefer, R.W.; Chipman, J.W. Remote Sensing and Image Interpretation, 7th ed.; John Wiley and Sons: New York, NY, USA, 2015; ISBN 978-1-118-34328-9.

10. Campbell, J.B.; Wynne, R.H. Introduction to Remote Sensing, 5th ed.; The Guilford Press: New York City, NY, USA, 2011; ISBN 978-1-60918-176-5.

11. Richards, J.A. Remote Sensing Digital Image Analysis An Introduction; Springer: Heidelberg, Germany, 2013; ISBN 978-3-642-30062-2.

12. Gómez-Palacios, D.; Torres, M.A.; Reinoso, E. Flood mapping through principal component analysis of multitemporal satellite imagery considering the alteration of water spectral properties due to turbidity conditions. Geomat. Nat. Hazards Risk 2016, 1-17. [CrossRef]

13. Stark, B.; Member, S.; Mcgee, M.; Member, S.; Chen, Y.; Member, S. Short Wave Infrared ( SWIR ) Imaging Systems Using Small Unmanned Aerial Systems (sUAS). In Proceedings of the 2015 International Conference on Unmanned Aircraft Systems (ICUAS), Denver, CO, USA, 9-12 June 2015; pp. 495-501. [CrossRef]

14. Vanhellemont, Q.; Ruddick, K. Remote Sensing of Environment Advantages of high quality SWIR bands for ocean colour processing: Examples from Landsat-8. Remote Sens. Environ. 2015, 161, 89-106. [CrossRef]

15. Shi, W.; Wang, M. Detection of turbid waters and absorbing aerosols for the MODIS ocean color data processing. Remote Sens. Environ. 2007, 110, 149-161. [CrossRef] 
16. Brakenridge, G.R.; Syvitski, J.P.M.; Niebuhr, E.; Overeem, I.; Higgins, S.A.; Kettner, A.J.; Prades, L. Design with nature: Causation and avoidance of catastrophic flooding, Myanmar. Earth-Sci. Rev. 2017, 165, 81-109. [CrossRef]

17. Dao, P.D.; Liou, Y.A. Object-based flood mapping and affected rice field estimation with landsat 8 OLI and MODIS data. Remote Sens. 2015, 7, 5077-5097. [CrossRef]

18. Kugler, Z.; De Groeve, T.; De Groeve, T. The Global Flood Detection System; Office for Official Publications of the European Communities: Luxembourg, 2007; p. 45.

19. Revilla-Romero, B.; Hirpa, F.A.; del Pozo, J.T.; Salamon, P.; Brakenridge, R.; Pappenberger, F.; de Groeve, T. On the use of global flood forecasts and satellite-derived inundation maps for flood monitoring in data-sparse regions. Remote Sens. 2015, 7, 15702-15728. [CrossRef]

20. Ding, X.; Nunziata, F.; Li, X.; Migliaccio, M. Performance Analysis and Validation of Waterline Extraction Approaches Using Single- and Dual-Polarimetric SAR Data. IEEE J. Sel. Top. Appl. Earth Obs. Remote Sens. 2015, 8, 1019-1027. [CrossRef]

21. Oberstadler, R.; Ho, Ã.H. Assessment of the Mapping Capabilities of ERS-1 SAR Data for Flood Mapping: A Case Study in Germany. Hydrol. Process. 1997, 11, 1415-1425. [CrossRef]

22. Smith, L.C. Sattelite Remote Sensing of River Inundation Area, Stage, and Discharge: A Review. Hydrol. Process. 1997, 11, 1427-1439. [CrossRef]

23. Yesou, H.; Andreoli, R.; Fellah, K.; Tholey, N.; Clandillon, S.; Bastiton, S.; Allenbach, B.; Meyer, C.; Bestault, C.; Fraipont, P. Large plain flood mapping and monitoring based on EO data. IGARRSS 2007. [CrossRef]

24. Wang, W.; Yang, X.; Li, X.; Chen, K.; Liu, G.; Li, Z.; Gade, M. A Fully Polarimetric SAR Imagery Classification Scheme for Mud and Sand Flats in Intertidal Zones. IEEE Trans. Geosci. Remote Sens. 2017, 55, 1734-1742. [CrossRef]

25. Bates, P.D.; Wilson, M.D.; Horritt, M.S.; Mason, D.C.; Holden, N.; Currie, A. Reach scale floodplain inundation dynamics observed using airborne synthetic aperture radar imagery: Data analysis and modelling. J. Hydrol. 2006, 328, 306-318. [CrossRef]

26. Boni, G.; Ferraris, L.; Pulvirenti, L.; Squicciarino, G.; Pierdicca, N.; Candela, L.; Pisani, A.R.; Zoffoli, S.; Onori, R.; Proietti, C.; et al. A Prototype System for Flood Monitoring Based on Flood Forecast Combined with COSMO-SkyMed and Sentinel-1 Data. IEEE J. Sel. Top. Appl. Earth Obs. Remote Sens. 2016, 9, 2794-2805. [CrossRef]

27. Martinis, S.; Kuenzer, C.; Wendleder, A.; Huth, J.; Twele, A.; Roth, A.; Dech, S. Comparing four operational SAR-based water and flood detection approaches. Int. J. Remote Sens. 2015, 36, 3519-3543. [CrossRef]

28. Pulvirenti, L.; Pierdicca, N.; Chini, M.; Guerriero, L. An algorithm for operational flood mapping from Synthetic Aperture Radar (SAR) data using fuzzy logic. Nat. Hazards Earth Syst. Sci. 2011, 11, 529-540. [CrossRef]

29. Pulvirenti, L.; Marzano, F.S.; Pierdicca, N.; Mori, S.; Chini, M. Discrimination of water surfaces, heavy rainfall, and wet snow using COSMO-SkyMed observations of severe weather events. IEEE Trans. Geosci. Remote Sens. 2014, 52, 858-869. [CrossRef]

30. Chini, M.; Hostache, R.; Giustarini, L.; Matgen, P. A Hierarchical Split-Based Approach for Parametric Thresholding of SAR Images: Flood Inundation as a Test Case. IEEE Trans. Geosci. Remote Sens. 2017, 1-14. [CrossRef]

31. Ulaby, F.T.; Dobson, M.C. Handbook of Radar Scattering Statistics for Terrain; Artech House: Norwood, MA, USA, 1989; ISBN 0890063362.

32. Matgen, P.; Hostache, R.; Schumann, G.; Pfister, L.; Hoffmann, L.; Savenije, H.H.G. Towards an automated SAR-based flood monitoring system: Lessons learned from two case studies. Phys. Chem. Earth 2011, 36, 241-252. [CrossRef]

33. Schlaffer, S.; Matgen, P.; Hollaus, M.; Wagner, W. Flood detection from multi-temporal SAR data using harmonic analysis and change detection. Int. J. Appl. Earth Obs. Geoinf. 2015, 38, 15-24. [CrossRef]

34. EU Directive 2007/60/EC of the European Parliament and of the Council of 23 October 2007 on the assessment and management of flood risks. Off. J. Eur. Union 2007, 288, 2007.

35. Coppin, P.; Jonckheere, I.; Nackaerts, K.; Muys, B.; Lambin, E. Digital change detection methods in ecosystem monitoring: A review. Int. J. Remote Sens. 2004, 25, 1565-1596. [CrossRef]

36. Disperati, L.; Virdis, S.G.P. Assessment of land-use and land-cover changes from 1965 to 2014 in Tam Giang-Cau Hai Lagoon, central Vietnam. Appl. Geogr. 2015, 58, 48-64. [CrossRef] 
37. Cenci, L.; Disperati, L.; Persichillo, M.G.; Oliveira, E.R.; Alves, F.L.; Phillips, M. Integrating remote sensing and GIS techniques for monitoring and modeling shoreline evolution to support coastal risk management. GIScience Remote Sens. 2017, 1-21. [CrossRef]

38. Li, Y.; Gong, X.; Guo, Z.; Xu, K.; Hu, D.; Zhou, H. An index and approach for water extraction using Landsat-OLI data. Int. J. Remote Sens. 2016, 37, 3611-3635. [CrossRef]

39. Ji, L.; Zhang, L.; Wylie, B. Analysis of Dynamic Thresholds for the Normalized Difference Water Index. Photogramm. Eng. Remote Sens. 2009, 75, 1307-1317. [CrossRef]

40. Lu, D.; Mausel, P.; Brondízio, E.; Moran, E. Change detection techniques. Int. J. Remote Sens. 2004, 25, 2365-2407. [CrossRef]

41. Singh, A. Review Articlel: Digital change detection techniques using remotely-sensed data. Int. J. Remote Sens. 1989, 10, 989-1003. [CrossRef]

42. Rouse, J.W.; Hass, R.H.; Schell, J.A.; Deering, D.W. Monitoring vegetation systems in the great plains with ERTS. In Proceedings of the NASA. Goddard Space Flight Center 3d ERTS-1 Symp., College Station, TX, USA, 1 January 1974; Volume 1, pp. 309-317.

43. $\mathrm{Xu}, \mathrm{H}$. Modification of normalised difference water index (NDWI) to enhance open water features in remotely sensed imagery. Int. J. Remote Sens. 2006, 27, 3025-3033. [CrossRef]

44. Zhai, K.; Wu, X.; Qin, Y.; Du, P. Comparison of surface water extraction performances of different classic water indices using OLI and TM imageries in different situations. Geo-Spat. Inf. Sci. 2015, 18, 32-42. [CrossRef]

45. Feyisa, G.L.; Meilby, H.; Fensholt, R.; Proud, S.R. Automated Water Extraction Index: A new technique for surface water mapping using Landsat imagery. Remote Sens. Environ. 2014, 140, 23-35. [CrossRef]

46. Kauth, R.J.; Thomas, G.S. The tasselled cap-A graphic description of the spectral-temporal development of agricultural crops as seen by Landsat. In Proceedings of the Symposium on Machine Processing of Remotely Sensed Data, West Lafayette, IN, USA, 29 June-1 July 1976; pp. 41-51.

47. Crist, E.P.; Cicone, R.C. A Phisically-Based Transformation of Thematic Mapper Data-The Tasseled Cap. IEEE Trans. Geosci. Remote Sens. 1984, 22, 256-263. [CrossRef]

48. Crist, E.P. A TM Tasseled Cap equivalent transformation for reflectance factor data. Remote Sens. Environ. 1985, 17, 301-306. [CrossRef]

49. Fisher, A.; Flood, N.; Danaher, T. Comparing Landsat water index methods for automated water classification in eastern Australia. Remote Sens. Environ. 2016, 175, 167-182. [CrossRef]

50. Baig, M.H.A.; Zhang, L.; Shuai, T.; Tong, Q. Derivation of a tasselled cap transformation based on Landsat 8 at-satellite reflectance. Remote Sens. Lett. 2014, 5, 423-431. [CrossRef]

51. Huang, C.; Wylie, B.; Yang, L.; Homer, C.; Zylstra, G. Derivation of a Tasseled cap transformation based on Landsat 7 at-satellite reflectance. Int. J. Remote Sens. 2002, 23, 1741-1748. [CrossRef]

52. Devries, B.; Pratihast, A.K.; Verbesselt, J.; Kooistra, L.; Herold, M. Characterizing forest change using community-based monitoring data and landsat time series. PLOS ONE 2016, 11, e0147121. [CrossRef] [PubMed]

53. Fang-fang, Z.; Bing, Z.; Jun-sheng, L.; Qian, S.; Yuanfeng, W.; Yang, S. Comparative Analysis of Automatic Water Identification Method Based on Multispectral Remote Sensing. Procedia Environ. Sci. 2011, 11, 1482-1487. [CrossRef]

54. Gao, H.; Wang, L.; Jing, L.; Xu, J. An effective modified water extraction method for Landsat-8 OLI imagery of mountainous plateau regions. In IOP Conference Series: Earth and Environmental Science; IOP Publishing: Bristol, UK, 2016; Volume 34, p. 012010. [CrossRef]

55. Zhou, Y.; Dong, J.; Xiao, X.; Xiao, T.; Yang, Z.; Zhao, G.; Zou, Z.; Qin, Y. Open surface water mapping algorithms: A comparison of water-related spectral indices and sensors. Water 2017, 9, 256. [CrossRef]

56. Rokni, K.; Ahmad, A.; Selamat, A.; Hazini, S. Water feature extraction and change detection using multitemporal landsat imagery. Remote Sens. 2014, 6, 4173-4189. [CrossRef]

57. Yarbrough, L.D.; Easson, G.; Kuszmaul, J.S. Using at-sensor radiance and reflectance Tasseled Cap transforms applied to change detection for the ASTER sensor. In Proceedings of the International Workshop on the Analysis of Multi-Temporal Remote Sensing Images, Biloxi, MS, USA, 16-18 May 2005; Volume 2005, pp. 141-145. [CrossRef]

58. Ivits, E.; Lamb, A.; Langar, F.; Hemphill, S.; Koch, B. Orthogonal Transformation of Segmented SPOT5 Images: Seasonal and Geographical Dependence of the Tasselled Cap Parameters. Photogramm. Eng. Remote Sens. 2008, 74, 1351-1364. [CrossRef] 
59. Nedkov, R. Orthogonal transformation of segmented images from the satellite sentinel-2. C. R. L'Academie Bulg. Sci. 2017, 70, 687-692.

60. Feng, Q.; Gong, J.; Liu, J.; Li, Y. Flood mapping based on multiple endmember spectral mixture analysis and random forest classifier-the case of yuyao, China. Remote Sens. 2015, 7, 12539-12562. [CrossRef]

61. Xiao, X.; Wdowinski, S.; Wu, Y. Improved water classification using an application-oriented processing of landsat ETM+ and ALOS PALSAR. Int. J. Control Autom. 2014, 7, 373-388. [CrossRef]

62. Memon, A.A.; Muhammad, S.; Rahman, S.; Haq, M. Flood monitoring and damage assessment using water indices: A case study of Pakistan flood-2012. Egypt. J. Remote Sens. Sp. Sci. 2015, 18, 99-106. [CrossRef]

63. Brivio, P.A.; Colombo, R.; Maggi, M.; Tomasoni, R. Integration of remote sensing data and GIS for accurate mapping of flooded areas. Int. J. Remote Sens. 2002, 23, 429-441. [CrossRef]

64. Bartsch, A.; Pathe, C.; Wagner, W.; Scipal, K. Detection of permanent open water surfaces in central Siberia with ENVISAT ASAR wide swath data with special emphasis on the estimation of methane fluxes from tundra wetlands. Hydrol. Res. 2008, 39, 89-100. [CrossRef]

65. Smith, L.C.; Isacks, B.L.; Forster, R.; Bloom, A.L.; Preuss, I. Estimation of Discharge From Braided Glacial Rivers Using ERS 1 Synthetic Aperture Radar: First Results. Water Resour. Res. 1995, 31, 1325-1329. [CrossRef]

66. Smith, L.C.; Isacks, B.L.; Murray, A.B.; Smith, L.C.; Isacks, B.L.; Bloom, A.L.; Murray, A.B. Estimation of Discharge From Three Braided Rivers Using Synthetic Aperture Radar Satellite Imagery: Potential Application to Ungaged Basins. Water Resour. Res. 1996, 32, 2021-2034. [CrossRef]

67. Otsu, N. A Threshold Selection Method from Gray-Level Histograms. IEEE Trans. Syst. Man Cybern. 1979, 9, 62-66. [CrossRef]

68. Hess, L.L.; Melack, J.M.; Davis, F.W. Mapping of Floodplain Inundation with Multi-Frequency Polarimetric SAR: Use of a Tree-Based Model. Int. J. Ecol. Environ. Sci. 1994, 11, 1072-1073.

69. Giustarini, L.; Hostache, R.; Matgen, P.; Schumann, G.J.; Bates, P.D.; Mason, D.C. A Change Detection Approach to Flood Mapping in Urban Areas Using TerraSAR-X. IEEE Trans. Geosci. Remote Sens. 2013, 51, 2417-2430. [CrossRef]

70. Martinis, S.; Kersten, J.; Twele, A. A fully automated TerraSAR-X based flood service. ISPRS J. Photogramm. Remote Sens. 2015, 104, 203-212. [CrossRef]

71. Martinis, S.; Twele, A.; Voigt, S. Towards operational near real-time flood detection using a split-based automatic thresholding procedure on high resolution TerraSAR-X data. Nat. Hazards Earth Syst. Sci. 2009, 9, 303-314. [CrossRef]

72. Cenci, L.; Boni, G.; Pulvirenti, L.; Squicciarino, G.; Gabellani, S.; Gardella, F.; Pierdicca, N.; Chini, M. Monitoring reservoirs' water level from space for flood control applications. A case study in the Italian Alpine region. In Proceedings of the 2017 IEEE International Geoscience and Remote Sensing Symposium (IGARSS), Fort Worth, TX, USA, 23-28 July 2017; pp. 5617-5620. [CrossRef]

73. Schowengerdt, R.A. Remote Sensing: Models and Methods for Image Processing, 3rd ed.; Academic Press: Cambridge, MA, USA, 2007; ISBN 978-0-12-369407-2.

74. Zhu, Z.; Woodcock, C.E. Remote Sensing of Environment Object-based cloud and cloud shadow detection in Landsat imagery. Remote Sens. Environ. 2012, 118, 83-94. [CrossRef]

75. Hughes, M.J.; Hayes, D.J. Automated Detection of Cloud and Cloud Shadow in single-date Landsat imagery using neural networks and spatial post-processing. Remote Sens. 2014, 6, 4907-4926. [CrossRef]

76. Braaten, J.D.; Cohen, W.B.; Yang, Z. Remote Sensing of Environment Automated cloud and cloud shadow identi fi cation in Landsat MSS imagery for temperate ecosystems. Remote Sens. Environ. 2015, 169, 128-138. [CrossRef]

77. Fisher, A. Cloud and Cloud-Shadow Detection in SPOT5 HRG Imagery with Automated Morphological Feature Extraction. Remote Sens. 2014, 6, 776-800. [CrossRef]

78. Hulley, G.C.; Hook, S.J. A new methodology for cloud detection and classification with ASTER data. Geophys. Res. Lett. 2008, 35, 1-6. [CrossRef]

79. Irish, R.R.; Barker, J.L.; Goward, S.N.; Arvidson, T. Characterization of the Landsat-7 ETM+ Automated Cloud-Cover Assessment (ACCA) Algorithm. Photogramm. Eng. Remote Sens. 2006, 72, 1179-1188. [CrossRef]

80. Scaramuzza, P.L.; Bouchard, M.A.; Dwyer, J.L. Development of the Landsat Data Continuity Mission Cloud-Cover Assessment Algorithms. IEEE Trans. Geosci. Remote Sens. 2012, 50, 1140-1154. [CrossRef] 
81. NASA Shuttle Radar Topography Mission (SRTM). Available online: https://www2.jpl.nasa.gov/srtm/ (accessed on 1 March 2019).

82. NASA Advanced Spaceborne Thermal Emission and Reflection Radiometer (ASTER). Available online: https://asterweb.jpl.nasa.gov/gdem.asp (accessed on 1 March 2019).

83. JAXA ALOS Global Digital Surface Model “ALOS World 3D-30m (AW3D30)". Available online: https: //www.eorc.jaxa.jp/ALOS/en/aw3d30/ (accessed on 1 March 2019).

84. Yamazaki, D.; Ikeshima, D.; Tawatari, R.; Yamaguchi, T.; O'Loughlin, F.; Neal, J.C.; Sampson, C.C.; Kanae, C.; Bates, P.D. MERIT DEM: Multi-Error-Removed Improved-Terrain DEM. Available online: http://hydro.iis.u-tokyo.ac.jp/ \{\}yamadai/MERIT_DEM/ (accessed on 1 March 2019).

85. Azevedo, A.; Fortunato, A.B.; Epifânio, B.; den Boer, S.; Oliveira, E.R.; Alves, F.L.; de Jesus, G.; Gomes, J.L.; Oliveira, A. An oil risk management system based on high-resolution hazard and vulnerability calculations. Ocean Coast. Manag. 2017, 136,1-18. [CrossRef]

86. Sousa, L.P.; Sousa, A.I.; Alves, F.L.; Lillebø, A.I. Ecosystem services provided by a complex coastal region: Challenges of classification and mapping. Sci. Rep. 2016, 6, 1-14. [CrossRef]

87. Sena, C.; de Melo, M.T.C. Groundwater-surface water interactions in a freshwater lagoon vulnerable to anthropogenic pressures (Pateira de Fermentelos, Portugal). J. Hydrol. 2012, 466-467, 88-102. [CrossRef]

88. Alves, F.L.; Sousa, L.P.; Silva, J.V.; Dias, J.M.; Lopes, C.; Coelho, C.; Pereira, C. ADAPTARia-Modelação das Alterações Climáticas No Litoral da Ria de Aveiro Estratégias de Adaptaçãp para Cheias Costeiras e Fluviais; Tarefa 2. Revisão do Estado-da-arte, Recolha e Análise de Dados; Universidade de Aveiro: Aveiro, Portugal, 2010.

89. CMI. Estratégia Municipal de Adaptação às Alterações Climáticas no Município de Ílhavo; CMI: Ílhavo, Portugal, 2016.

90. APA SNIRH. Available online: http://snirh.pt/ (accessed on 1 March 2019).

91. Raes, D. Frequency analysis of rainfall data. In College on Soil Physics-30th Anniversary (1983-2013); International Centre for Theoretical Physics: Trieste, Italy, 2013; Volume 42. [CrossRef]

92. Drusch, M.; Del Bello, U.; Carlier, S.; Colin, O.; Fernandez, V.; Gascon, F.; Hoersch, B.; Isola, C.; Laberinti, P.; Martimort, P.; et al. Remote Sensing of Environment Sentinel-2: ESA's Optical High-Resolution Mission for GMES Operational Services. Remote Sens. Environ. 2012, 120, 25-36. [CrossRef]

93. Santillan, J.R.; Makinano-Santinano-Santillan, M. Vertical Accuracy Assessment of 30-M Resolution ALOS, ASTER, and SRTM Global DEMS over Northeastern Mindanao, Philippines. In Proceedings of the International Archives of the Photogrammetry, Remote Sensing and Spatial Information Sciences, Prague, Czech Republic, 12-19 July 2016; Volume XLI-B4, pp. 12-19.

94. Purinton, B.; Bookhagen, B. Validation of digital elevation models ( DEMs ) and comparison of geomorphic metrics on the southern Central Andean Plateau. Earth Surf. Dyn. 2017, 211-237. [CrossRef]

95. USGS Landsat Surface Reflectance Quality Assessment. Available online: https://landsat.usgs.gov/landsatsurface-reflectance-quality-assessment (accessed on 1 March 2019).

96. RMS. Beaufort Scale for Land Areas; RMS: Reading, UK, 2015.

97. Wang, M.; Shi, W.; Tang, J. Remote Sensing of Environment Water property monitoring and assessment for China's inland Lake Taihu from MODIS-Aqua measurements. Remote Sens. Environ. 2011, 115, 841-854. [CrossRef]

98. Woodhouse, I.H.; Marino, A.; Cameron, I. A standard index of spatial resolution for distributed targets in synthetic aperture radar imagery. Int. J. Remote Sens. 2011, 32, 7929-7938. [CrossRef]

(C) 2019 by the authors. Licensee MDPI, Basel, Switzerland. This article is an open access article distributed under the terms and conditions of the Creative Commons Attribution (CC BY) license (http://creativecommons.org/licenses/by/4.0/). 